Illinois State University

ISU ReD: Research and eData

Theses and Dissertations

7-3-2015

\title{
Bacterially-Based Immune Challenges And Trauma Elicit Terminal Investment In Male Aedes Aegypti
}

Molly K. Schumacher

Illinois State University, mkschum@gmail.com

Follow this and additional works at: https://ir.library.illinoisstate.edu/etd

Part of the Allergy and Immunology Commons, Biology Commons, Entomology Commons, Immunology and Infectious Disease Commons, and the Medical Immunology Commons

\section{Recommended Citation}

Schumacher, Molly K., "Bacterially-Based Immune Challenges And Trauma Elicit Terminal Investment In Male Aedes Aegypti" (2015). Theses and Dissertations. 443.

https://ir.library.illinoisstate.edu/etd/443

This Thesis is brought to you for free and open access by ISU ReD: Research and eData. It has been accepted for inclusion in Theses and Dissertations by an authorized administrator of ISU ReD: Research and eData. For more information, please contact ISUReD@ilstu.edu. 


\title{
BACTERIALLY-BASED IMMUNE CHALLENGES AND TRAUMA ELICIT TERMINAL INVESTMENT IN
}

\author{
MALE AEDES AEGYPTI
}

\author{
Molly K. Schumacher
}

64 Pages

August 2015

Investment in life history traits such as immune function and reproduction is constrained by finite available resources. A cost-of-immunity trade-off may occur in response to infection when resources are diverted away from reproductive effort and into an immune response. Alternatively, an infected individual may enhance reproductive effort to maximize terminal reproductive success in response to the survival threat inherent to infection (terminal investment). We measured male Aedes aegypti reproductive behavior following inoculations with: living bacteria; killed bacteria as an immune elicitor; and a sham control. Mating competitiveness relative to naïve males was also determined through a binary mate choice experiment using wild-type and eye-color mutant populations to assess paternity. We found that male mating behaviors did not differ among immune challenge treatments, but immune challenged males had greater mating success relative to naïve males, consistent with terminal investment. Though previous experiments using similar immune challenges in females show induction of immune responses, our treatments yielded no detectable effect in males based on two standard physiological immune assays. However, the eye-color mutants had high levels 
of immune function relative to the wild-type males. Male terminal investment has the potential to improve the success of sterile male release programs that rely on male mating performance to control mosquito populations. Increasing male sexual competitiveness after sterilization is an emerging topic within insect behavioral ecology, and illustrates the important role of evolutionary theory in contributing to the efficacy of these population control strategies for medically and economically important pests. 
BACTERIALLY-BASED IMMUNE CHALLENGES AND

TRAUMA ELICIT TERMINAL INVESTMENT IN

MALE AEDES AEGYPTI

MOLLY K. SCHUMACHER

A Thesis Submitted in Partial Fulfillment of the Requirements for the Degree of

MASTER OF SCIENCE

School of Biological Sciences

ILLINOIS STATE UNIVERSITY 
(C) 2015 Molly K. Schumacher 
BACTERIALLY-BASED IMMUNE CHALLENGES AND TRAUMA ELICIT TERMINAL INVESTMENT IN

MALE AEDES AEGYPTI

MOLLY K. SCHUMACHER

COMMITTEE MEMBERS:

Steven A. Juliano, Chair

Ben M. Sadd

Scott K. Sakaluk 


\section{ACKNOWLEDGMENTS}

I am thankful to past and current members of the Juliano lab at Illinois State University, most notably Jennifer Breaux for training and scientific inspiration, Katie Westby for being my field guide and tramping around NOLA for mosquito collection, Geoff Ower for colony maintenance and egg donations, Joe Oremus for mosquito husbandry, Pat McCormick for wing length measurements, and Andrew Goodman for behavioral assay assistance. Additional thanks are given to Craig Gatto, Charitha Galva, Dawn Wesson, Paul Garris, Brian Wilkinson and Deborah Petrik for access to materials, and the graduate students for their continued inspiration and comradery. This project was not possible without my committee members, whom I have the utmost respect for and have considered me an honorary lab member: Scott Sakaluk for his comments and suggestions regarding the behavioral assays and mating behaviors, and Ben Sadd for extensive training and use of his lab and materials, and overall support and encouragement throughout the study. I am indebted to my advisor, Steven Juliano, who recruited me into the field of mosquito ecology as an impressionable undergraduate, and has been a wonderful mentor and supportive advisor throughout my scientific endeavors. Finally, thank you to Chris Faulkner for your sympathy, encouragement, and compassion, and for picking up the slack in the real world while I pursued my academic efforts, and my family for their praise and support. 


\section{CONTENTS}

Page

ACKNOWLEDGMENTS $\quad$ i

CONTENTS

TABLES $\quad$ iv

FIGURES

CHAPTER

I. BACTERIALLY-BASED IMMUNE CHALLENGES AND TRAUMA ELICIT TERMINAL INVESTMENT IN MALE AEDES AEGYPTI 1

Lay Summary 1

Abstract 1

Introduction $\quad 2$

$\begin{array}{ll}\text { Methods } & 7\end{array}$

$\begin{array}{ll}\text { Mosquito Husbandry } & 8\end{array}$

Immune Challenges $\quad 9$

$\begin{array}{ll}\text { Mating Trials } & 10\end{array}$

Measures of Male Immunity 13

$\begin{array}{ll}\text { Statistical Analyses } & 16\end{array}$

$\begin{array}{ll}\text { Results } & 20\end{array}$

$\begin{array}{ll}\text { Survival } & 20\end{array}$

Behavioral Assay $\quad 21$

Binary Mate Trials $\quad 22$

Measures of Male Immunity 23

Discussion 24

Funding $\quad 32$

Animal Treatment $\quad 32$

References $\quad 33$ 
Table

II. QUANTIFYING SEXUAL PERFORMANCE IN YELLOW FEVER MOSQUITOES (DIPTERA: CULICIDAE) USING EXOGENOUS MATING CUES AND RAPID TIME LAPSE PHOTOGRAPHY

Abstract

Keywords

Introduction

Methods

Study Organism

Animal Husbandry

Behavioral Assay Materials and Methods

Results

Discussion

53

References

57

Table

61

Figures 


\section{TABLES}

Table $\quad$ Page

1.1 Multiple Contrasts of Behavioral Assays and Binary Mate Trials 39

2.1 Male Aedes aegypti Mating Behaviors 61 


\section{FIGURES}

$\begin{array}{lll}\text { Figure } & \text { Page }\end{array}$

1.1 Inheritance of Wild-Type and White-Eyed Mutant Phenotypes 40

1.2 Proportion of Mating Trials Where a Male Successfully Sired Offspring 41

1.3 Measures of Innate Immunity for Male Phenotype 42

2.1 Materials and Methods of Behavioral Assays 62

2.2 Observable Behaviors of Male and Female A. aegypti 63

2.3 Inseminated and Un-inseminated Spermathecae 64 


\title{
CHAPTER I
}

\section{BACTERIALLY-BASED IMMUNE CHALLENGES AND TRAUMA ELICIT TERMINAL INVESTMENT IN}

\author{
MALE AEDES AEGYPTI
}

\section{Lay Summary}

On encountering an infectious pathogen, males should invest in immune defense, but if the infection is severe and signals impending death, invest in reproduction. When competing against unchallenged males, male yellow-fever mosquitoes receiving an immune challenge, signaling a survival threat, had higher mating success than control males, supporting the latter prediction. Infection-enhanced mating success may be valuable for mosquito control strategies based on releasing sterile, yet sexually competitive males.

\begin{abstract}
Investment in life history traits such as immune function and reproduction is constrained by finite available resources. A cost-of-immunity trade-off may occur in response to infection when resources are diverted away from reproductive effort and into an immune response upregulation. Alternatively, an infected individual may enhance reproductive effort to maximize terminal reproductive success in response to the survival threat
\end{abstract}


inherent to infection (terminal investment). We measured male Aedes aegypti reproductive behavior following inoculations with: living bacteria; killed bacteria as an immune elicitor; and a sham control. Mating competitiveness relative to naïve males was also determined through a binary mate choice experiment using wild-type and eye-color mutant populations to assess paternity. We found that male mating behaviors did not differ among immune challenge treatments, but immune challenged males had greater mating success relative to naïve males, consistent with terminal investment. Though previous experiments using similar immune challenges in females show induction of immune responses, our treatments yielded no detectable effect in males based on two standard physiological immune assays. However, the eye-color mutants had higher levels of immune function relative to the wild-type males. Male terminal investment has the potential to improve the success of sterile male release programs that rely on male mating performance to control mosquito populations. Increasing male sexual competitiveness after sterilization is an emerging topic within insect behavioral ecology, and illustrates the important role of evolutionary theory in contributing to the efficacy of these population control strategies for medically and economically important pests.

\section{Introduction}

Life history theory suggests that investment and allocation of resources to traits such as reproduction, growth and immune function all require investment of material resources, resulting in trade-offs among these traits that impact lifetime fitness of an individual (Sheldon and Verhulst 1996; Ahmed et al. 2002; Zuk and Stoehr 2002; Ahmed and Hurd 2006; Sadd et al. 2006). For insects that are no longer growing after adult 
eclosion, two key life history traits are reproduction and pathogen resistance, often equated with immune investment. Finite resources dictate a coupling between these life history traits, which will frequently manifest in reduced reproductive effort upon infection due to investment into costly immunity. However, if the perceived threat to survival imposed by pathogen infection is large terminal investment into current reproduction is an alternative outcome.

Upregulating immune defense is costly (Sheldon and Verhulst 1996; Hosken 2001; Ahmed et al. 2002; Ahmed and Hurd 2006; Sadd and Schmid-Hempel 2009), and though defense against or elimination of an infection has obvious advantages, the high cost may result in restriction of resources that can be invested in reproduction (Sheldon and Verhulst 1996; Hurd 2001; Zuk and Stoehr 2002; Jacot et al. 2004; Ahmed and Hurd 2006; Lawniczak et al. 2007; Contreras-Garduño et al. 2009; Kerr et al. 2010; Nystrand and Dowling 2014). For males, courtship (Marden and Cobb 2004; Kerr et al. 2010), mate guarding (Low 2006), male-male interactions (Marden and Cobb 2004), territoriality (Contreras-Garduño et al. 2009), sperm quantity and quality (Simmons 2012; McNamara et al. 2013) and investment in substances that manipulate female post copulatory behavior (Perry et al. 2013) may all be compromised upon infection. Some of these results can be explained by virulence, with infection altering physiological functions through tissue damage or nutrient deficiencies (Harrison et al. 2001), or resources the pathogen appropriates from the host that the host requires for vigorous physical activity and endurance, metabolism, and mobility necessary for male courting and sexual signals (Schall 1982; Munger and Karasov 1989; Marden and Cobb 2004). 
Perhaps even more interesting is the observation that simple immune challenges consisting of killed pathogens or benign immune elicitors can cause a decrease in courting quality and quantity in males (Jacot et al. 2004; Kerr et al. 2010), suggesting that costs of immunity are central to this response. The negative relationship between immune defense and current reproduction may manifest itself through the reallocation of resources, which would otherwise be used for reproduction, into fighting an infection, and thus, enabling that individual to achieve greater lifetime fitness by increasing their longevity and future reproduction (Jacot et al. 2004; Contreras-Garduño et al. 2009). This forms the basis of the Cost-of-Immunity Hypothesis.

As an alternative to the Cost-of-Immunity Hypothesis, the Terminal Investment Hypothesis postulates that in response to the survival threat represented by a pathogenic infection, an individual may enhance resource allocation to current reproduction to compensate for the potential loss of future reproduction events (Clutton-Brock 1984; Sadd et al. 2006; Kivleniece et al. 2010). This enhanced allocation to current reproduction comes at a cost: reduced immune function, reduced future reproduction, and possibly decreased longevity (Kivleniece et al. 2010). However, if longevity is reduced due to infection, lifetime fitness of terminal investing individuals will exceed that of infected individuals that do not shift investment to accelerate reproduction. The phenomenon of terminal investment has been described in numerous invertebrate taxa, including the decorated cricket (Kerr et al. 2010), mealworm beetle (Sadd et al. 2006), burying beetle (Creighton et al. 2009), and cotton bollworm (McNamara et al. 2013). 
Exploiting plasticity in life-history traits by manipulating males into increasing reproduction could be of practical use for insect control methods that rely on the success of male mating behavior. Reproductive success of male mosquitoes is central to several population control strategies in which males are mass released into wild populations, mate with wild females, and produce inviable eggs or offspring (e.g., sterile insect technique via radiation sterilization (SIT); release of insects carrying a dominant lethal allele (RIDL)) (Alphey et al. 2010; Oliva et al. 2013; Pérez-Staples et al. 2013). These males must be behaviorally competent to compete for mates: they necessarily must locate, court, and mate with females to produce inviable offspring required for the success of these programs (Alphey et al. 2010; 2013; Pérez-Staples et al. 2013). Sterile release strategies have had limited success (Benedict and Robinson 2003), in part due to the poor performance of males after sterilization (Lopez-Martinez and Hahn 2012), and in part because females may avoid mating with released males (Alphey et al. 2013), though this possibility has not been empirically tested. We know that radiation sterilization reduces male fruit fly flight performance, female attraction, and mating success (Nestel et al. 2007; Lopez-Martinez and Hahn 2012) and similar trends are apparent in sterilized mosquitoes. Sterile Aedes males inseminate fewer females relative to wild type males, and are unable to replenish sperm supplies after depletion (Oliva et al. 2013), and mating ability declines with increasing irradiation dose when males are sterilized as pupae (Helinski et al. 2006). For a more detailed review of the mating failures of sterile male release strategies, see Pérez-Staples et al. (2013). 
Manipulating male fruit flies to increase sexual performance has been achieved via anoxic conditioning (Lopez-Martinez and Hahn 2012) and semiochemical and hormonal dietary supplements (for a review see Pereira et al. 2013). Despite the potential benefits of improving sexual performance for sterile male release programs, attempts to enhance mating success of males via application of evolutionary life-history theory, such as the terminal investment hypothesis, are nonexistent.

In this study, we tested the reproductive responses of male Aedes aegypti to actual or simulated bacterial infection as a means of distinguishing the alternative hypotheses of cost-of-immunity or terminal investment. We inoculated males with living Escherichia coli, heat-killed E. coli, or sterile saline. This latter group was a sham control for integument injury because injection through integument alone represents physiological trauma, and can induce immune upregulation (Korner and Schmid-Hempel 2004; Wigby et al. 2008). Based on our hypotheses, we predicted that challenged males will either: (1) shift investment of resources away from reproduction and towards immunity, which in turn predicts that challenged males will have decreased frequency and duration of mating behaviors, and decreased probability of mating relative to naïve males (Cost-ofImmunity Hypothesis); or (2) increase reproductive effort, which in turn predicts an increased frequency and duration of mating behaviors, and a higher probability of mating relative to naïve males (Terminal Investment Hypothesis). The purpose of this paper is to report a test of these alternative hypotheses using male Aedes aegypti, a medically and economically important vector of dengue, chikingunya, and yellow-fever viruses. Ahmed et al. (2002) report decreased reproductive output of female Anopheles gambiae 
following immune stimulation, and similar findings are reported in malaria infected females (Ahmed and Hurd 2006), providing evidence for the Cost-of-Immunity Hypothesis. While the Terminal Investment Hypothesis has never been directly demonstrated in mosquitoes, Ponlawat and Harrington (2007) found that older male $A$. aegypti have higher reproductive success relative to young males, suggesting support of the terminal investment hypothesis when the survival threat is increased age rather than a pathogenic infection.

\section{Methods}

To determine how immune challenge treatments alter frequency and duration of mating behaviors, immune challenged (see below) or naïve males were paired with females in behavioral assays and video recorded to quantify behaviors that are necessary for mating: approaching and mounting females, copulation, and time spent flying, as mating is typically initiated in swarms (Roth 1948; Williams and Berger 1980). To determine success of immune challenged males in competition for mates with naïve males, immune challenged and naïve males were paired in binary mating trials with a single female, and the "winner" of those trials was determined based on phenotypes of resulting offspring. To determine the role, if any, of altered immune function in this system we assayed phenoloxidase activity (PO) to assess investment into the melanization response and the humoral antimicrobial activity through zone of inhibition assays. In other insect systems, phenoloxidase activity is associated with encapsulation and is an indicator of an organism's capacity to resist pathogens (Wilson et al. 2001; Rantala and Roff 2007), but it's titers return to baseline levels within 12-24 hours post 
immune challenge (Korner and Schmid-Hempel 2004). In contrast, measurable induction of humoral antimicrobial activity, including action of antimicrobial peptides (AMPs) such as cecropin that provides a strong defense against gram-negative bacteria in Diptera, can persist for several days (Vernick 1997) or weeks (Korner and Schmid-Hempel 2004; Schmid-Hempel 2005).

\section{Mosquito Husbandry}

First instar wild-type New Orleans, LA, USA (NOLA, several generations in the laboratory) and mutant (recessive KHW white eyed mutant; MRA-730-CDC, obtained through the MR4 BEI Resources Repository, NIAID, NIH) Aedes aegypti larvae ( $n=$ 100) were raised at $28^{\circ} \mathrm{C}, 60 \%$ relative humidity and $14: 10 \mathrm{~h}$ light:dark photoperiod (hereafter "standard A. aegypti conditions") in $1 \mathrm{~L}$ white polystyrene beakers containing $300 \mathrm{~mL}$ of live oak (Quercus virginiana) infusion (105 g dry leaves in $3 \mathrm{~L}$ reverse osmosis (RO) water, and aged 5 days under standard A. aegypti conditions), $700 \mathrm{~mL}$ nanopure water, and $0.08 \mathrm{~g}$ lactalbumin, a larval diet supplement. Larvae were provided $0.05 \mathrm{~g}$ and $0.02 \mathrm{~g}$ lactalbumin 5 and 7 days post larval addition, respectively. Pupae were collected daily and stored individually in screened vials $(15 \mathrm{~mL}, 21 \times 70 \mathrm{~mm})$ to ensure virginity. Water was extracted from the vials once a day as adults eclosed. Females were provided ad libitum sucrose (1:20 sucrose:RO water on cotton pads, replenished every other day), whereas males were provided sucrose solution for the first $24 \mathrm{~h}$ post eclosion. 


\section{Immune Challenges}

At $24 \mathrm{~h}$ post eclosion, males were sucrose starved for $24 \mathrm{~h}$ (provided $\mathrm{RO}_{2} \mathrm{O}$ on a cotton pad) in an effort to limit reserves prior to immune challenge, thus, increasing the probability of a trade-off between life history traits. Males were ice anesthetized in screened glass vials for 2-4 min and given one of three immune challenge treatments: living DH5 $\alpha$ E. coli (Stratagene) suspended in sterile phosphate buffered saline, heatkilled E. coli suspended in sterile PBS, or sterile PBS as a sham control. Populations of $E$. coli were grown overnight in liquid LB medium $\left(37^{\circ} \mathrm{C}, 200 \mathrm{rpm}, 7 \mathrm{~h}\right)$ and diluted to $10^{9}$ cells per mL (Murdock et al. 2013). The suspension was centrifuged (10000 rpm, $6 \mathrm{~min}$ ), the supernatant replaced with sterile PBS and vortexed. This procedure was repeated $3 \mathrm{x}$ and the final pellet was re-suspended in PBS. A portion of this suspension was heat-killed on a heat block $\left(90^{\circ} \mathrm{C}, 7 \mathrm{~min}\right)$ and stored at $-80^{\circ} \mathrm{C}$. For treatments, a sterile pulled capillary tube $(50 \mu \mathrm{L}, 100 \mathrm{~cm})$ was dipped into solutions representing each of the immune challenge solutions then used to puncture lateral thoracic membrane between the paratergite and sternopleuron sclerites of anesthetized males. Additionally, naïve control males were cold anesthetized, positioned laterally on a stereoscope and then returned to the glass vial. Bacterial solutions were used for a maximum of $1 \mathrm{~h}$ post preparation due to the increasing probability of cell death via osmosis. Samples of the living and heat-killed E. coli and sterile PBS were plated on $1.5 \% \mathrm{LB}$ agar and incubated at $37^{\circ} \mathrm{C}$ overnight to ensure growth of living E. coli solutions, and no growth of heat-killed E. coli and PBS solutions. Males were returned to the glass vial, housed at standard A. aegypti conditions and provided $5 \%$ sucrose solution for $36 \mathrm{~h}$ post inoculation, followed by a $12-20 \mathrm{~h}$ liquid 
starvation. All males had a minimum $48 \mathrm{~h}$ post-inoculation recovery period, a time period sufficient to resume normal behavior and flight capability (Helinski et al. 2012). Wing length of each male in mating trials was recorded as a measure of overall size (Christophers 1960).

\section{Mating Trials}

\section{Behavioral Assay}

Mating trials were conducted using NOLA males that were 12-20 $\mathrm{h}$ liquid starved, and NOLA females that were 0-2 days younger than the male in that mating trial. Males were placed into (diameter $\mathrm{x}$ height $=8.5 \times 8.5 \mathrm{~cm}$ ) paper cups with a $\sim 2 \mathrm{~cm}$ diameter hole in the side of for mosquito transfer, a mesh bottom, and a $15 \times 15 \mathrm{~cm}$ Plexiglas ${ }^{\circledR}$ top (="arenas"), and allowed to acclimate for $1 \mathrm{~h}$ in an observation room $\left(27^{\circ} \mathrm{C}, 20 \%\right.$ relative humidity, 15.5:8.5 light:dark photoperiod). Females acclimated for $1 \mathrm{~h}$ in screened glass vials, then were transferred to the arena through the hole in the side. To provide the pair additional mating cues, three arenas and cameras were secured with Velcro® onto a plastic cutting board and transferred to a large wood and plastic screened cage $\left(60 \mathrm{~cm}^{3}\right.$ cage, with a $60 \times 20 \mathrm{~cm}$ sleeve-covered hole in the front bottom face for mosquito transfer) containing a colony of NOLA $A$. aegypti that were allowed to swarm, to produce aggregation pheromones, and to mate. Males will swarm near hosts to attract females (Cator et al. 2011; Helinski and Harrington 2012), and male and female mating behavior is stimulated by host cues such as carboxylic acid found in human foot odors (Owino et al. 2014, 2015). Therefore, we added to the colony cage 2 socks that had been worn the 
day before and stored in a plastic bag to stimulate swarming and sexual behavior. Aedes aegypti mating is also stimulated after they take flight (Christophers 1960), and can be induced by continually disturbing mosquito cages (Williams and Berger 1980). Therefore, we placed a $56 \mathrm{~cm}$ table-top tower fan (Wexford®, low speed/oscillation) behind the colony cage to provide air movement to disturb the colony and to promote flight activity.

Behavioral assays were recorded for $1 \mathrm{~h}$ using time-lapse photography (1 frame per $2 \mathrm{sec}$ ) on GoPro Hero 3 (Woodman Labs Inc. (C) cameras (Schumacher et al, in review). After the trial, males were aspirated into screened glass vials, whereas females were aspirated into white $1 \mathrm{~L}$ polyethylene containers (height x diameter: 114x119 mm) where they remained for 1-6 days post mating trial, until we dissected them to determine if there were sperm in their spermathecae (Benedict 2014), and to confirm male mating success. We provided males and females 5\% ad libitum sucrose, and recorded survival every other day and every 4 days for males and females, respectively. The first 1200 frames after female entrance into the arena were used for behavioral data collection. We scored observable behaviors necessary for mating for each male: number of frames flying; number of frames mounting/grasping a female; number of approaches to a female; latency to approach a female; latency to mating, and mating success, which was scored when the male and female took ventral, face-to-face position with physical contact of genitalia (Roth 1948; Helinski and Harrington 2012). Success or failure of mating was cross-checked via determining presence or absence of sperm in the female's spermatheca. 


\section{Binary Mating Trials}

Binary mating choice trials between a single immune challenged male (either inoculated with living E. coli, heat-killed E. coli, or sterile PBS) and a naïve control male were run to determine if immune challenged males can compete successfully for access to females relative to naïve males. Because video resolution was not sufficient to distinguish the two males while in flight, behavior was not quantified in binary trials. Instead, we determined mating success by determining the phenotypes of resulting larval offspring. Males in the binary mating trials were from the lines mentioned above: whiteeyed mutants and wild-type NOLA, whereas females were exclusively white-eyed mutants. The mutant phenotype is observable in first-instar larva and is determined by a single recessive allele inherited with $100 \%$ penetrance (Bhalla 1968). Thus, offspring from a white-eyed females will either be wild-type or white-eyed mutant if the male sire is wild-type or white-eyed, respectively (Bhalla 1968; Clements 1992, Figure 1.1). To ensure no bias due to an innate preference of females for male phenotype, we alternated the assignment of immune challenge treatments or naïve controls across trials (i.e., males were: immune challenged=white-eyed mutant vs. naïve control=wild-type or immune challenged=wild-type vs. naïve control=white-eyed).

NOLA and mutant A. aegypti males and females were reared as described above in separate replicate containers. After liquid starvation, a single white-eyed female, along with a naïve control and an immune challenged male (either inoculated with living $E$. coli, heat-killed $E$. coli, or sterile PBS) were transferred into the screened polyethylene mating arenas (described above) which was secured to a $\sim 15 \times 15 \mathrm{~cm}$ sheet of clear 
Plexiglas ${ }^{\circledR}$. We housed arenas in standard A. aegypti conditions, provided ad libitum 5\% sucrose solution, and recorded survival daily. Mating trials lasted 4 days unless a mosquito died, in which case the entire trial was removed from the paternity assays but remained in survival assays. Males were aspirated into $15 \mathrm{~mL}$ vials, whereas females remained in mating arenas. We offered all males and females ad libitum 5\% sucrose and recorded survival every other day and every 4 days for males and females, respectively.

Females were offered a blood meal from an anesthetized mouse (IACUC protocol \#01-2013) upon termination of the mating trial. Females that did not blood feed were offered up to two additional blood meals on subsequent days, and those that did not blood feed after three feeding attempts were eliminated from the study. Two-to-four days post blood meal, gravid females were provided a black polystyrene beaker $(50 \mathrm{~mL})$ lined with seed germination paper and filled with $35 \mathrm{~mL}$ of $4: 3 \mathrm{x}$ water:oak infusion (described above), for oviposition. Beakers were replaced after 7 days, and eggs allowed to embryonate in A. aegypti conditions for 7 days, then dried and hatched in nutrient broth ( $0.4 \mathrm{~g}$ per L RO water). Number of eggs laid was recorded as a measure of female fecundity. First instar larvae were scored for white-eyed or wild-type phenotype using a stereoscope, determining the sire of the offspring, and thus the "winner" of male binary choice mating trials.

\section{Measures of Male Immunity}

Subsamples of males from each inoculation treatment were randomly selected after $12 \mathrm{~h}$ liquid starvation period (the same period used in mating trials) and frozen and 
stored in a $1.5 \mathrm{~mL}$ screw top Eppendorf ${ }^{\circledR}$ tubes at $-80^{\circ} \mathrm{C}$ for future immune assays. Phenoloxidase Assay

Melanization is a humoral, non-specific immune defense against a range of pathogens that are encapsulated by hemocytes and melanized, a process that depends on the activation of phenoloxidase (PO) (Schmid-Hempel 2005; Cerenius et al. 2008; Nunn et al. 2009). Pro-phenoloxidase is quickly activated in the hemolymph upon wounding or infection (Hosken 2001) and the speed at which it is converted can be measured using a spectrophotometric assay (Kohlmeier et al. 2015).

Mosquitoes were homogenized (Bead Ruptor $12 \AA$ ) for $30 \mathrm{~s}$ with a $2.4 \mathrm{~mm}$ bead and $50 \mu \mathrm{L}$ PBS on high $(5 \mathrm{~m} / \mathrm{s})$. Homogenates were centrifuged $\left(3000 \mathrm{rpm}, 4^{\circ} \mathrm{C}, 5 \mathrm{~min}\right)$ and $35 \mu \mathrm{L}$ of supernatant was snap frozen in liquid nitrogen and stored at $-80^{\circ} \mathrm{C}$. We thawed samples on ice and added $15 \mu \mathrm{L}$ of the unknown sample or $15 \mu \mathrm{L}$ PBS as a control to flat-bottomed 96-well plates containing $20 \mu \mathrm{L}$ PBS and $140 \mu \mathrm{L}$ RO water, and mixed by pipetting. We then added $20 \mu \mathrm{L}$ of RO water saturated with L-Dopa (4 mg per $\mathrm{mL} \mathrm{H}_{2} 0 ; 3,4$ dihyroxyl L-phenyla) to each well, and the solutions were shaken for $5 \mathrm{~s}$ at $30^{\circ} \mathrm{C}$ in a spectrophotometer (Multiskan $\mathrm{GO}{ }^{\circledR}$, Thermal Scientific). Active PO activity (measured by the slope of the reaction curve in its linear phase) was determined by measuring absorbance $(490 \mathrm{~nm})$ every $15 \mathrm{~s}$ for 160 readings with a spectrophotometer. Duplicate plates were measured for each sample to obtain at least one successful reading, or to determine the mean of 2 successful readings. 


\section{Zone of Inhibition}

In insects, AMPs are produced several hours after infection or injury (Hosken 2001) and are an important mode of defense against various microbes (Nystrand and Dowling 2014). Antibacterial activity, including the action of AMPs, can be quantified by plating samples on bacteria seeded agar and measuring the diameter of zones around the samples with inhibited growth following incubation (Ahmed et al. 2002).

We homogenized individual mosquitoes (Bead Ruptor $12 ®)$ on high $(5 \mathrm{~m} / \mathrm{s})$ for $30 \mathrm{~s}$ in a $1.5 \mathrm{~mL}$ screw-top Eppendorf® tube containing a $2.4 \mathrm{~mm}$ bead and $25 \mu \mathrm{L}$ of Anticoagulant II (Mead et al. 1986). We centrifuged the homogenates $\left(10000 \mathrm{rpm}, 4^{\circ} \mathrm{C}, 5\right.$ min) and transferred $10 \mu \mathrm{L}$ of supernatant to a new Eppendorf® tube, snap froze samples in liquid nitrogen and stored them at $-80^{\circ} \mathrm{C}$.

\section{A single colony of Arthrobacteur globiformus (DSM No. 20124, DSZM}

Braunschweig, Germany) was grown overnight in liquid LB medium in a shaking incubator $\left(30^{\circ} \mathrm{C}, 250 \mathrm{rpm}\right)$. A $1 \% \mathrm{LB}$ agar $(\mathrm{pH} 7.2-7.5)$ was prepared, autoclaved, and cooled in a water bath $\left(45^{\circ} \mathrm{C}, 45 \mathrm{~min}\right)$. Once cooled, we mixed $A$. globiformus into the agar so that the final concentration was $10^{5}$ cells $/ \mathrm{mL}$, and distributed evenly $7 \mathrm{~mL}$ onto sterile $10 \mathrm{~cm}$ petri plates and allowed them to cool. Sample wells (10 per plate) were stamped out using a sterilized Pasteur Pipette (150 mm, Volac \#D810), and $2 \mu \mathrm{L}$ of the prepared sample was added to each well with $2 \mu \mathrm{L}$ of Anticoagulant II (negative control). A positive control of $2 \mu \mathrm{L}$ tetracycline $(0.004 \mathrm{mg}$ per $\mathrm{mL})$ was added to a well on a separate plate prepared simultaneously. After $20 \mathrm{~min}$, plates were inverted and incubated 
at $30^{\circ} \mathrm{C}$ for $18 \mathrm{~h}$. Due to a low resolution of zones of inhibition from the mosquitoes, we could not accurately measure zone diameters; hence we recorded data as presence or absence of a zone for each sample.

\section{Statistical Analyses}

All statistical analyses were performed in SAS 9.3 (SAS Institute Inc. 2011).

\section{Male Survival}

We analyzed effects of immune challenge on male survival using a proportional hazard survival analysis (PROC PHREG). Longevity was censored for males that were assayed for immune function, and for males that were accidentally killed. To ensure that the outcome of the mating trials did not depend on males of a particular treatment or phenotype dying during the mating trials, an additional proportional hazards survival analysis (PROC PHREG) was performed on age at death over the first 8 days, with any male that lived beyond the mating trial termination (i.e., day 8 post adult eclosion) counted as censored.

\section{Behavioral Assay}

For proportion of observations a male spent flying and mounting, the data did not meet assumptions of normality and homogeneity of variances even after several transformations and use of a Poisson distribution of errors. Instead, we analyzed the number of frames flying and mounting a female, along with the number of approaches to a female with a mixed effects ANOVA (PROC GLIMMIX) with a zero inflated Poisson 
distribution (Leisnham et al. 2014) and a log link function. Our sampling unit for video trials was 1200 frames, though some trials contained slightly fewer frames. Trials were not considered if they contained 1180 frames or less $(1.67 \%$ deviation from our target sampling unit), which removed 9 trials from the data set because of camera battery failure. Trials that contained between 1180-1199 frames occurred due to accidental deletion of a few frames from the ends of trials. Due to fluorescent light failure in 2 mating trials, light status (fluorescent or incandescent) was tested as a main effect in the models. Light status improved Akaike Information Criterion (AICc) in the analysis of number of frames flying, but not in the analysis of number of frames a male spent mounting a female, the number of approaches to a female, mating success, or latencies to approach or to mate. Random effects of mating trial, larval rearing block, order in which cameras starting recording, day of adult eclosion, and sock status were tested in each model, and none of these improved AICc; hence they were excluded.

We analyzed latency to approach a female or to a mating event with a survival analysis (PROC PHREG) to generate hazard ratios, and performed pairwise contrasts of immune challenge treatments. Those that did not approach or mate with a female were recorded as censored observations (latency $=2360-2400 \mathrm{~s}$ depending on total number of frames).

To determine if immune challenge treatment affected mating, we used mixedeffects ANOVA (PROC GLIMMIX) with a logit link function, where mating success was recorded as a binary variable (yes or no). We were interested in four specific hypotheses that we tested using contrasts among treatment groups (Table 1.1). We follow 
Rosenthall and Rosnow (1985) and focus on contrasts regardless of whether or not the overall ANOVA yielded a $P<0.05$. First we tested whether inoculation differed from naïve (Table 1.1; punctured vs. none). Second, we tested whether inoculation with bacteria (living or heat-killed) differed from sterile inoculation (Table 1.1; sterile vs. bacterial puncture). Third, we tested whether inoculation with living bacteria differed from inoculation with dead bacteria (Table 1.1; living vs. heat-killed). These 3 contrasts were orthogonal; we also tested one non-orthogonal contrast, testing whether sterile inoculation differed from naïve (Table 1.1; sterile vs. none). We corrected for multiple comparisons using the false discovery rate (FDR; Waite and Campbell 2006). The random effects listed above again did not improve AICc, and they were excluded from the model. Mating success was cross-referenced with female spermatheca dissection data, and mating is only considered successful if a female was inseminated. There were 4 mating trials where mating status=no, but the female's spermatheca contained sperm. Because copulation was not observed in the videos, we infer that copulation occurred after the trial ended but before the male and female were separated. We elected to regard them as unmated because we did not see mating in the time allotted in the video recording.

Binary Mate Choice Trials

We analyzed the binary mate choice trials using a mixed effects ANOVA (PROC GLIMMIX) with the male immune challenge treatment and phenotype as main effects and sire status (binary variable: yes or no) as the categorical dependent variable with binomial error and a logit link function. Mating trial was included as a random effect to 
account for the linked responses for the two males in a trial. We used the same orthogonal and non-orthogonal contrasts (described above) to test four specific hypotheses, and corrected for multiple comparisons using the false discovery rate (Table 1.1). To determine if males affected female fecundity, a random effects ANOVA (PROC MIXED) was performed on number of eggs laid by the female with treatment and phenotype as main effects, and mosquito rearing block as a random effect.

\section{Measures of Male Immunity}

To determine if male treatment or phenotype affected PO activity, the rate of PO activity increase $\left(\mathrm{V}_{\max }\right)$ was calculated as the slope of the reaction curve at its linear phase (Kohlmeier et al. 2015). We $\log _{10}$ transformed and analyzed this variable using a mixed effects ANOVA (PROC MIXED) with male treatment and phenotype as main effects and larval rearing blocks as a random effect. Other random effects (e.g., 96-well plate block, adult eclosion cohort) were tested but removed from the model as they did not improve AICc. To determine if male immune challenge treatment or phenotype affected presence of measureable antimicrobial activity, a mixed effects ANOVA (PROC GLIMMIX) with a logit link function was performed including larval rearing block and different batches of agar as random variables. The interaction of male treatment*phenotype was tested, but removed from the model as it was not significant and did not improve the model AICc. To investigate further the difference between naïve control males and those that received an immune challenge, we tested a contrast of naïve control males versus the three immune challenged groups (inoculated with living E. coli, heat-killed E. coli or sterile PBS) for both immune assays. 


\section{Mosquito Size}

We had wing measurements only for individuals that died young $(n=50 / 112$ and $n=59 / 160$ males for behavioral analyses and binary mate choice experiments, respectively). During lab rearing, wings become damaged and unmeasurable with increased age at death. To test whether wing length as a covariate had statistically important effects, we analyzed these smaller data sets (i.e., only males that had measureable wings) with and without the covariate wing length. Models without wing length always yielded better AICc. Thus, we elected to disregard wing length, and used the entire data set for all analyses reported.

\section{Results}

\section{Survival}

Eighty percent of inoculated males lived beyond the end of the binary mate choice trials (i.e., 8 days post adult eclosion). Immune challenge treatment did not affect overall survival (Wald $\chi^{2}{ }_{3}=3.5805, P=0.3105$ ), or survival during the first 8 days post adult eclosion, which constitutes the critical period for the mating trials (Wald $\chi^{2}{ }_{3}=6.4419, P$ $=0.0920)$. Phenotype affected overall survival, with white-eyed mutants having a greater hazard of death than wild-type males (Wald $\chi^{2}{ }_{1}=40.0017, P=<0.0001$ ), but did not similarly affect survival during the first 8 days post adult eclosion (Wald $\chi^{2}{ }_{1}=2.0172, P$ $=0.1555)$. There was a marginally non-significant interaction of treatment*phenotype in the first 8 days post adult eclosion (Wald $\chi^{2}{ }_{3}=7.6128, P=0.0547$ ), but this effect was not significant when total survival was considered (Wald $\chi^{2}{ }_{3}=3.0414, P=0.3853$ ). As 
expected, we found a significant larval rearing block effect when overall survival was considered (Wald $\chi^{2}{ }_{18}=60.5523, P=<0.001$ ), but this did not affect survival during the first 8 days post eclosion (Wald $\chi^{2} 18=22.9741, P=0.1916$ ).

\section{Behavioral Assay}

Out of 103 males, only 4 did not fly in the 40 min. Immune challenge treatment did not affect the flight of males $\left(F_{3,97}=0.97, P=0.409\right)$. Trials under fluorescent vs. incandescent lights yielded significantly different frequencies of flight (ANOVA, $F_{2,97}=$ 7.40, $P=0.001)$ with male flying greater under incandescent light. Male immune challenge treatment affected neither the number of frames spent mounting a female (ANOVA, $F_{3,99}=0.81, P=0.3974$ ) nor the number of times approaching a female (ANOVA, $\left.F_{3,86}=0.80, P=0.4945\right)$.

Out of 103 males that were video recorded and assessed for mating behaviors, 39 males approached females, and 15 successfully mated (censored observations 64 and 88 respectively). Male immune challenge treatments did not affect latency to approach (Wald $\chi^{2}{ }_{3}=3.212, P=0.36$ ) or to mate with a female (Wald $\chi^{2}{ }_{3}=3.292, P=0.3488$ ). Immune challenge treatment also did not affect overall mating success (ANOVA, $F_{3,99}=$ 1.15, $P=0.3346$ ), and orthogonal and non-orthogonal contrasts indicated no significant differences in mating success between: males punctured vs. not punctured (i.e., living $E$. coli + heat-killed E. coli + sham vs. naïve); males inoculated with E. coli (living or heatkilled) vs. sterile PBS; males inoculated with living vs. heat-killed E. coli; and males inoculated with sterile PBS vs. naïve males (Table 1.1). 


\section{Binary Mate Trials}

A total of 92 mating trials produced offspring enabling determination of the sire. Males from 12 of these mating trials were inoculated with PBS that had become contaminated with living $E$. coli (confirmed by negative control plates) and we elected to eliminate trials that contained these males. The control plates indicated no contamination of the living or heat-killed $E$. coli for that round of inoculations, so these trials were included in the analysis. These 80 trials included 30 males inoculated with living E. coli, 33 males inoculated with heat-killed $E$. coli, and 17 males inoculated with sterile PBS, each paired with a naïve male $(n=80)$. Four females had offspring that were sired by 2 males, and in these cases both males were considered "winners" of their mating trials.

We found marginally non-significant effects of male immune challenge treatments on mating success (ANOVA, $\left.\chi^{2}{ }_{3}=7.05, P=0.0703\right)$. Contrasts indicated significantly greater mating success for punctured vs. not punctured (i.e., living E. coli + heat-killed E. coli + sham vs. naïve) males (Table 1.1, Figure 1.2b). There were no significant differences in success between males inoculated with E. coli (living or heatkilled) vs. sterile PBS (Table 1.1, Figure 1.2b), and no difference between males inoculated with living vs. heat-killed E. coli (Table 1.1, Figure 1.2b). There was a marginally non-significant difference in mating success between males inoculated with sterile PBS vs. naïve males (Table 1.1, Figure 1.2a). We found no significant effect of male phenotype on male mating success (ANOVA, $\chi^{2}{ }_{1}=0.04, P=0.8332$ ), indicating that females in these trials had no innate preference for wild-type $(n=80)$ vs. mutant $(n=$ 80) males. We found no effect of male treatment (ANOVA, $F_{1,64}=0.83, P=0.3660$ ), 
phenotype (ANOVA, $F_{3,64}=0.83, P=0.4819$ ), or their interaction (ANOVA, $F_{3,64}=0.77$, $P=0.5169)$ on female fecundity, indicating that reproductive success is largely determined by male ability to secure mates and to sire offspring, not male ability to manipulate females to lay more eggs.

\section{Measures of Male Immunity}

Phenoloxidase (PO) Activity

We tested PO activity of $n=42,30,24$, and 23 males from naïve control, living E. coli, heat-killed E. coli and sterile PBS groups, respectively. There was no significant treatment effect on PO activity (ANOVA, $\left.F_{3,110}=1.60, P=0.1939\right)$ and no significant difference between naïve control males vs. pooled immune challenged males (ANOVA, $\left.F_{1,110}=0.01, P=0.9281\right)$. Mutants $(n=32)$ had greater PO activity than did wild-type males $(n=87)\left(\right.$ ANOVA, $F_{1,110}=12.73, P=0.0005$, Figure $\left.1.3 \mathrm{a}\right)$ but there was no significant treatment*phenotype interaction effect on PO activity (ANOVA, $F_{3,110}=1.76$, $P=0.1585)$

\section{Antimicrobial Activity}

Of 82 , only 8 male homogenates produced clear zones of inhibition, and we found no effect of immune challenge on presence vs. absence of a zone of inhibition (ANOVA, $\left.\chi_{3}^{2}=3.47, P=0.325\right)$, and no significant difference between naïve control males vs. pooled immune challenged males (ANOVA, $\left.\chi^{2}{ }_{1}=0.00, P=0.9957\right)$. Male phenotype had a marginally non-significant effect (ANOVA, $\chi^{2}{ }_{1}=3.48, P=0.062$ ), with mutant 
males $(n=22)$ more frequently showing a zone of inhibition relative to wild type males $(n=60)$ (Figure 1.3b).

\section{Discussion}

We have demonstrated that males inoculated with different immune challenges (living E. coli, heat-killed E. coli or sterile PBS) have similar likelihood of successful mating in competition with naïve control males. When pooling these immune challenged males we find they are more likely to succeed in mating than competing naïve control males (Figure 1.2b). This result is, in some ways, opposite the trend observed among immune-challenged female mosquitoes. For example, Anopheles gambiae females show decreased reproductive output following inoculation with lipopolysaccharide (LPS) (Ahmed et al. 2002), or malaria (Ahmed and Hurd 2006). Thus, our data suggest males respond to potential immune challenges in a manner consistent with terminal investment, whereas past data of females suggest support for the cost-of-immunity hypothesis.

We did not reach this same conclusion when analyzing the single male behavioral assays: immune challenged and naïve males had indistinguishable probabilities of acquiring a mate in the 40 minute assays, and mating behaviors were unaffected by immune challenge treatments. One interpretation of this discrepancy in the results of our experiment is that the lack of male competition in the single-male behavioral assays did not provide a sufficiently stringent test of which males are more successful in acquiring mates. It is perhaps possible that these males in the single-male trials did not have an adequate amount of time to mate relative to males in the longer binary mating experiment 
(40 min vs. 4 days, respectively), though this seems unlikely, as A. aegypti copulation duration lasts an average of $10 \mathrm{~s}$ (Roth 1948, Ponlawat and Harrington 2009), and our behavioral assays show that some males start courting immediately upon introduction of the female. What is more probable is that males in the binary mating trials were prompted to mate when handled and disturbed daily to check for mortality. The additional disturbance over the 4 day trials likely prompted mating behaviors (Christophers 1960; Williams and Berger 1980) and though we provided a routine disturbance (i.e., oscillating fan) to males in the 40 minute behavioral assays, the binary trial males ultimately had more time and opportunities to mate. Additionally, mate choosiness is predicated to be greater when the chance of encountering another potential mate is greater (e.g., lek, dense populations, and highly mobile species) (Johnstone et al. 1996). Males and females in the behavioral assays may perceive more sexual signals relative to those in the binary mating trials (i.e., sexual signals of many conspecifics swarming in the cage vs. sexual signals of only two conspecifics, respectively). Females in the video behavioral assays may perceive a benefit by waiting for other potentially high quality males to court her, while females in the binary mating trials may mate with one of the two males in the trial because they detect no chance of encountering another male.

The interpretation that the three inoculation treatments were comparable in their effects on mating is supported by the immune assays that we performed. We found no differences in male immune responses, (active PO assay, zone of inhibition) even when the pooled immune challenged males were compared to naïve males. Further, we observed no treatment effect on male survival, which is the same result that has been 
observed in LPS-injected female Anopheles stephensi (Ahmed et al. 2002). An infected individual may buffer against early mortality if resource competition between life history traits is balanced in a way to maximize its fitness (i.e., increased longevity, decreased reproduction) (Hurd 2001; Ahmed et al. 2002), therefore longevity may not be a good indicator of immune function. It is possible that our concentration of $10^{9}$ living or heatkilled $E$. coli per $\mathrm{mL}$ was insufficient to elicit an immune response, but previous experiments using a concentration of $10^{9} \mathrm{E}$. coli cells per $\mathrm{mL}$ induced upregulated AMPs in Anopheles stephensi females (Murdock et al. 2013), and interestingly, a concentration lower by an order of magnitude $\left(10^{8} \mathrm{E}\right.$. coli cells per $\left.\mathrm{mL}\right)$ was successful at inducing cecropin production in female A. aegypti (JA Breaux, dissertation). Given that males are the smaller sex in the case of A. aegypti, with mean male dry mass about $75 \%$ that of females (Wormington and Juliano 2014), we considered a concentration of $10^{9} \mathrm{E}$. coli cells per $\mathrm{mL}$ sufficient, and perhaps extreme, to elicit an immune response. One explanation for detectable immune responses in female but not male A. aegypti is that males and females experience different costs and benefits of any given immune strategy. Males maximize fitness through frequent matings, whereas females do so via increased longevity or fecundity (Bateman 1948; Rolff 2001; Schmid-Hempel 2005). For example, in mosquitoes, it is necessary for a female to live long enough to mate, to search for blood meals, to synthesize eggs, and to locate oviposition substrates to complete a single gonotrophic cycle. Thus females are predicted to gain greater benefits from immune investment. Further, as vectors of blood-borne pathogens, female mosquitoes have a greater probability of exposure to parasites and pathogens during blood feeding, which 
we postulate would select for high sex-specific investment into immunity (Rolff 2002; Nunn et al. 2009). Male mosquitoes do not blood feed, and sexual dimorphism in PO activity is evident in other insect taxa (Rolff 2001; for a meta-analysis see Nunn et al. 2009), thus, sexually dimorphic investment into immune defenses is also expected in mosquitoes.

Given their smaller size, males may exhibit reduced baseline levels of antimicrobial activity, rendering the immune assays ineffective if they do not have the resolution to detect such low levels. Nystrand and Dowling (2014) found weak AMP signals in male Drosophila melanogaster when injected with LPS, and it has been suggested that large effects of inoculations via integument piercing on immunity make it difficult to discern differences among groups in immune traits (Wigby et al. 2008; see below). Additionally, our mosquitoes were reared under favorable conditions as larvae, and kept in benign conditions as adults. Immune challenges are often more pronounced when reared under stressful or nutrient limited conditions (Rolff et al. 2004; Nystrand and Dowling 2014), and this should be considered in future immune studies on male mosquitoes. We assayed immunity at $48 \mathrm{~h}$ post-immune challenge, as this corresponded to the initiation of mating trials, and it is likely that PO activity had by this time declined back to pre-inoculation levels. Though antimicrobial activity and AMP titers can persist for days or weeks after immune challenge (Vernick 1997; Korner and Schmid-Hempel 2004), only 8 of our homogenates produced any zones of inhibition, rendering this assay limited in its ability to generate strong conclusions. 
Immune assay resolution did not result in inability to detect differences in immune responses between mutant and wild-type males. We found a marginally nonsignificant difference in antimicrobial activity between mutant and wild-type NOLA males, though few homogenates produced zones of inhibition. We found a highly significant difference in PO activity between male phenotypes, indicating that the KHW white-eye mutant males have greater immune responses than do the wild-type NOLA males (Figure 1.3). The mutant males have a long history of laboratory-based inbreeding, as the colony was first established in 1965 (Bhalla 1968), whereas the NOLA males have been lab reared for 12-18 months. Surprisingly, previous studies show that inbreeding has no effect on immune defense in invertebrates (Stevens et al. 1997; Gerloff et al. 2003; Calleri et al. 2006; Rantala and Roff 2006), and adverse inbreeding effects may be dampened if deleterious mutations have been purged from family lines (Schmid-Hempel 2005). Selection would favor differential investment into immunity if the populations have different histories of parasite exposure. Because we only have two lines, it cannot be determined if this wild-type population is investing less into immunity, or alternatively, if the mutant population is heavily investing into immunity, relative to any other population.

As we measured two immune responses at one time point, and not total immune investment, we cannot draw strong conclusions about whether males diverted resources to or away from immune defense. To verify this, responses to consecutive immune challenges must be evaluated on the same individual to understand how immune responses vary throughout their lifetime (Ryder 2007). Such measurements of sequential 
immune investment are attainable in larger vertebrate and invertebrate species, in which a non-destructive blood or hemolymph sample is obtained for the immune assays; however, such measurements are impossible in mosquitoes, as our measurements of immune function are destructive (i.e., require entire homogenates). For animals like mosquitoes, a snapshot of several immune parameters is the best measurement of immune function (Adamo 2004), but absence of effects at one time-point do not exclude differences at other time-points or in other parameters.

In studies where insects are subjected to immune stimulations (e.g., heat-killed bacteria or LPS), sham-controls are often administered to account for the difference between immune stimulation and the trauma inflicted by the antigen administration. Though animals that receive sham inoculations are often considered "un-stimulated", integument piercing and wounding may have substantial effects on immune responses (Wigby et al. 2008; Adamo 2010), especially in small insects. First, the insect cuticle surface is home to abundant opportunistic bacteria that enter the epithelium and hemolymph during wounding or piercing (Brey et al. 1993). Second, cellular and humoral immune responses are activated in the cuticular epithelium upon wounding or integument piercing. The wound must be healed to prevent further hemolymph loss, hence hemocytes are recruited and PO is activated for defense against invading pathogens and for melanization for cuticle scherlotization (Ashida and Brey 1998; Siva-Jothy et al. 2005). Further, AMP expression is upregulated after integument piercing (Wigby et al. 2008). Stress hormones such as the neurohormone octopamine are also released upon immune challenge and are hypothesized to facilitate the energy release that is required for 
enhanced immune function (Adamo and Parsons 2006; Adamo 2010). Similar physiological responses (i.e., upregulated levels of the stress hormone corticosterone) induce terminal investment in female house wrens (Bowers et al. 2015). It is possible that stress hormones, or the combination of immune responses and stress hormones, serve as a signal for a short life in insects. Sham punctures do not affect octopamine levels in crickets (Gryllus texensis) (Adamo 2010), indicating that a puncture alone does not trigger a stress response. We know nothing about the relationship between puncture wounding and octopamine levels in mosquitoes, and we cannot assume that mosquitoes' responses would be similar to those of crickets. Given that mosquitoes are considerably smaller than crickets, mosquitoes would likely perceive a puncture as a greater survival threat relative to crickets.

Our immune assays did not detect differences between immune challenged and naïve males (perhaps because of low assay resolution or low immune investment in males). However, the mosquitoes treated with immune challenges responded differently than did naïve controls. We found evidence of terminal investment following an integument puncture delivering living bacteria, heat-killed bacteria, or sterile PBS. Given that our living bacterial challenge was non-pathogenic, and that integument piercing might eclipse minor differences in immune responses (Wigby et al. 2008), we may not expect strong differences among our immune challenge treatments as all three were delivered via integument piercing. If all three of our immune challenge treatments were perceived the same way (i.e., indicating low probability of surviving trauma), then the males would likely behave similarly in all immune challenge treatments, which is what 
we observe. This result may be interpreted as indicating that terminal investment is provoked in our mosquitoes by the damage inflicted by physical trauma, over and above the cue from live bacteria or immune stimulation by heat-killed bacteria. If the response to physical trauma alone is costly and diverts a large supply of resources towards immune defense and cuticle repair, in turn acting as a signal for impending death, terminal investment may be the optimal strategy for maximizing lifetime fitness of a male mosquito subjected to such trauma.

The greater mating success of punctured males in male-male competition with naïve males (Figure 1.2) may prove valuable as a potential means to enhance mating success of sterile males in efforts to control mosquito populations via sterile-male release or RIDL (release of insects with a dominant lethal allele). Treating males in ways that artificially increase male mating competitiveness (e.g., inducing trauma) after sterilization could improve the efficiency of these control programs. Further investigations of terminal investment in males should include: First, identification of the physiological mechanisms leading to terminal investment and greater mating success in males that have received a puncture. Second, tests of terminal investment for males that have been sterilized or carry the RIDL genes, as there could be an interaction between the immune challenge or trauma and the sterilization process. Third, a more efficient method of challenging or traumatizing male mosquitoes would be needed for any use in mass release control programs, as manually inoculating the many males used in such programs is impractical. The current strategy to overcome decreased sexual competitiveness in sterile males is to release sufficient numbers so that they numerically outcompete the 
wild population of males (Alphey et al. 2010), but this approach is neither cost nor time effective. Additionally, the high ratio of male:female mosquitoes will have negative effects on male competition (Pérez-Staples et al. 2013), where the more dense the male population, the more likely copulation is interrupted (Ponlawat and Harrington 2009; Helinski and Harrington 2012) and multiple insemination will occur (Ponlawat and Harrington 2009). Because manipulating male sexual competitiveness is becoming an increasingly popular topic for such control programs (Lopez-Martinez and Hahn 2012; Pereira et al. 2013; Pérez-Staples et al. 2013; Segoli et al. 2014), tests of basic behavioral and evolutionary theory to understand the mechanisms provoking terminal investment should be a priority for medically and economically important insects.

\section{Funding}

This research was supported in part by NIAID grant 1R15AI094322-01A1 and Illinois State University Research Office undergraduate support to SA Juliano, and by a Beta Lambda Chapter of Phi Sigma Weigel Grant and two Mockford-Thompson Summer Fellowships to MK Schumacher, as well as a STEM Teach and Lead Mentorship Grant from Bradley University.

\section{Animal Treatment}

Protocol no. 01-2013 for the use of vertebrate animals was approved by the Institutional Animal Care and Use Committee, Illinois State University 


\section{REFERENCES}

Adamo SA. 2004. How should behavioural ecologists interpret measurements of immunity? Anim Behav. 68:1443-1449.

Adamo SA. 2010. Why should an immune response activate the stress response? Insights from the insects (the cricket Gryllus texensis). Brain Behav Immun. 24:194-200.

Adamo SA., Parsons NM. 2006. The emergency life-history stage and immunity in the cricket, Gryllus texensis. Anim Behav. 72:235-244.

Ahmed A., Baggott SL, Maingon R, Hurd H. 2002. The costs of mounting an immune response are reflected in the reproductive fitness of the mosquito Anopheles gambiae. Oikos 97:371-377.

Ahmed AM, Hurd H. 2006. Immune stimulation and malaria infection impose reproductive costs in Anopheles gambiae via follicular apoptosis. Microbes Infect. $8: 308-315$.

Alphey L, Benedict M, Bellini R, Clark GG, Dame DA, Service MW, Dobson SL. 2010. Sterile-insect methods for control of mosquito-borne diseases: An analysis. Vector borne Zoonotic Dis. 10:295-311.

Alphey L, McKemey A, Nimmo D, Neira Oviedo M, Lacroix R, Matzen K, Beech C. 2013. Genetic control of Aedes mosquitoes. Pathog Glob Health 107:170-179.

Ashida M, Brey PT. 1998. Recent advances in research on the insect prophenoloxidase cascade. In: Brey PT, Hultmark D, editors. Molecular mechanisms of immune responses in insects. 1st ed. London: Chapman \& Hall. p. 135-172.

Bateman AJ. 1948. Intra-sexual selection in Drosophila. Heredity (Edinb). 2:349-368.

Benedict MQ. 2014. Dissecting spermathecae to determine insemination status. In: Methods in Anopheles Research. 4th ed. Atlanta, GA: Malaria Research and Reference Reagent Resource Center.

Benedict MQ, Robinson AS. 2003. The first releases of transgenic mosquitoes: An argument for the sterile insect technique. Trends Parasitol. 19:349-355.

Bhalla SC. 1968 Sep. White eye, a new sex-linked mutant of Aedes aegypti. Mosq News 28:380-385. 
Bowers EK, Bowden RM, Sakaluk SK, Thompson CF. 2015. Immune activation generates corticosterone-mediated terminal reproductive investment in a wild bird. Am Nat. 185:769-783.

Brey PT, Lee WJ, Yamakawa M, Koizumi Y, Perrot S, François M, Ashida M. 1993. Role of the integument in insect immunity: epicuticular abrasion and induction of cecropin synthesis in cuticular epithelial cells. Proc Natl Acad Sci USA. 90:62756279 .

Calleri D V, McGrail Reid E, Rosengaus RB, Vargo EL, Traniello JF a. 2006. Inbreeding and disease resistance in a social insect: effects of heterozygosity on immunocompetence in the termite Zootermopsis angusticollis. Proc Biol Sci. 273:2633-2640.

Cator LJ, Arthur BJ, Ponlawat A, Harrington LC. 2011. Behavioral observations and sound recordings of free-flight mating swarms of Ae. Aegypti (Diptera: Culicidae) in Thailand. J Med Entomol. 48:941-946.

Cerenius L, Lee BL, Söderhäll K. 2008. The proPO-system: pros and cons for its role in invertebrate immunity. Trends Immunol. 29:263-271.

Christophers SR. 1960. Aedes Aegpti (L.) the yellow ferver mosquito: Its life history, bionomics and structure. London: The Syndics of the Cambridge University Press.

Clements, AN. 1992. The biology of mosquitoes, Volume II: Development, nutrition, and reproduction. London: Chapman \& Hall.

Clutton-Brock TH. 1984. Reproductive effort and terminal investment in iteroparous animals. Am Nat 123:212-229.

Contreras-Garduño J, Córdoba-Aguilar A, Lanz-Mendoza H, Cordero Rivera A. 2009. Territorial behaviour and immunity are mediated by juvenile hormone: The physiological basis of honest signalling? Funct Ecol. 23:157-163.

Creighton JC, Heflin ND, Belk MC. 2009. Cost of reproduction, resource quality, and terminal investment in a burying beetle. Am Nat. 174:673-684.

Gerloff CU, B.K. O, P. S-H. 2003. Effects of inbreeding on immune response and body size in a social insect, Bombus terrestris. Funct Ecol. 17:582-589.

Harrison JF, Camazine S, Marden JH, Kirkton SD, Rozo A, Yang X. 2001. Mite not make it home: tracheal mites reduce the safety margin for oxygen delivery of flying honeybees. J Exp Biol. 204:805-814.

Helinski MEH, Harrington LC. 2012. The role of male harassment on female fitness for the dengue vector mosquito Aedes aegypti. Behav Ecol Sociobiol. 66:1131-1140. 
Helinski MEH, Parker AG, Knols BGJ. 2006. Radiation-induced sterility for pupal and adult stages of the malaria mosquito Anopheles arabiensis. Malar J. 5:41.

Hosken DJ. 2001. Sex and death: Microevolutionary trade-offs between reproductive and immune investment in dung flies. Curr Biol. 11:379-380.

Hurd H. 2001. Host fecundity reduction: A strategy for damage limitation? Trends Parasitol. 17:363-368.

Jacot A, Scheuber H, Brinkhof MWG. 2004. Costs of an induced immune response on sexual display and longevity in field crickets. Evolution 58:2280-2286.

Johnstone, RA, Reynolds, JD, Deutsch, JC. 1995. Mutual mate choice and sex differences in choosiness. Evolution. 50:1382-1391.

Kerr AM, Gershman SN, Sakaluk SK. 2010. Experimentally induced spermatophore production and immune responses reveal a trade-off in crickets. Behav Ecol. 21:647-654.

Kivleniece I, Krams I, Daukšte J, Krama T, Rantala MJ. 2010. Sexual attractiveness of immune-challenged male mealworm beetles suggests terminal investment in reproduction. Anim Behav. 80:1015-1021.

Kohlmeier P, Dreyer H, Meunier J. 2015. PO-CALC: A novel tool to correct common inconsistencies in the measurement of phenoloxidase activity. J Insect Physiol. 75:80-84.

Korner P, Schmid-Hempel P. 2004. In vivo dynamics of an immune response in the bumble bee Bombus terrestris. J Invertebr Pathol. 87:59-66.

Lawniczak MKN, Barnes AI, Linklater JR, Boone JM, Wigby S, Chapman T. 2007. Mating and immunity in invertebrates. Trends Ecol Evol. 22:48-55.

Leisnham PT, LaDeau SL, Juliano SA. 2014. Spatial and temporal habitat segregation of mosquitoes in Urban Florida. PLoS One 9.3:e91655.

Lopez-Martinez G, Hahn DA. 2012. Short-term anoxic conditioning hormesis boosts antioxidant defenses, lowers oxidative damage following irradiation and enhances male sexual performance in the Caribbean fruit fly, Anastrepha suspensa. J Exp Biol. 215:2150-2161.

Low M. 2006. The energetic cost of mate guarding is correlated with territorial intrusions in the New Zealand stitchbird. Behav Ecol. 17:270-276.

Marden JH, Cobb JR. 2004. Territorial and mating success of dragonflies that vary in muscle power output and presence of gregarine gut parasites. Anim Behav. 68:857-865. 
McNamara KB, van Lieshout E, Jones TM, Simmons LW. 2013. Age-dependent tradeoffs between immunity and male, but not female, reproduction. J Anim Ecol. $82: 235-244$.

Mead GP, Ratcliffe NA, Renwrantz LR. 1986. The separation of insect haemocyte types on Percoll gradients; methodology and problems. J Insect Physiol. 32:167-177.

Munger JC, Karasov WH. 1989. Sublethal parasites and host energy budgets : Tapeworm infection in white-footed mice. Ecology 70:904-921.

Murdock CC, Moller-Jacobs LL, Thomas MB. 2013. Complex environmental drivers of immunity and resistance in malaria mosquitoes. Proc R Soc B Biol Sci. 280:20132030.

Nestel D, Nemny-Lavy E, Mohammad Islam S, Wornoayporn V, Cáceres C. 2007. Effects of pre-irradiation conditioning of medfly pupae (Diptera: Tephritidae): hypoxia and quality of sterile males. Florida Entomol. 90:80-87.

Nunn CL, Lindenfors P, Pursall ER, Rolff J. 2009. On sexual dimorphism in immune function. Philos. Trans. R. Soc. Lond. B. Biol. Sci. 364:61-69.

Nystrand M, Dowling DK. 2014. Dose-dependent effects of an immune challenge at both ultimate and proximate levels in Drosophila melanogaster. J. Evol. Biol. 27:876888 .

Oliva CF, Damiens D, Vreysen MJB, Lemperière G, Gilles J. 2013. Reproductive strategies of Aedes albopictus (Diptera: Culicidae) and implications for the sterile insect technique. PLoS One 8: e78884.

Owino EA, Sang R, Sole CL, Pirk C, Mbogo C, Torto B. 2014. Field evaluation of natural human odours and the biogent-synthetic lure in trapping Aedes aegypti, vector of dengue and chikungunya viruses in Kenya. Parasit Vectors 7:451.

Owino EA, Sang R, Sole CL, Pirk C, Mbogo C, Torto B. 2015. An improved odor bait for monitoring populations of Aedes aegypti-vectors of dengue and chikungunya viruses in Kenya. Parasit Vectors 8:1-12.

Pereira R, Yuval B, Liedo P, Teal PEA, Shelly TE, Mcinnis DO, Hendrichs J. 2013. Improving sterile male performance in support of programmes integrating the sterile insect technique against fruit flies. J Appl Entomol. 137:178-190.

Pérez-Staples D, Shelly TE, Yuval B. 2013. Female mating failure and the failure of "mating" in sterile insect programs. Entomol Exp Appl. 146:66-78.

Perry JC, Sirot L, Wigby S. 2013. The seminal symphony: How to compose an ejaculate. Trends Ecol Evol. 28:414-422. 
Ponlawat A, Harrington LC. 2009. Factors associated with male mating success of the dengue vector mosquito, Aedes aegypti. Am J Trop Med Hyg. 80:395-400.

Rantala MJ, Roff DA. 2007. Inbreeding and extreme outbreeding cause sex differences in immune defence and life history traits in Epirrita autumnata. Heredity (Edinb). 98:329-336.

Rantala MJ, Roff DA. 2006. Analysis of the importance of genotypic variation, metabolic rate, morphology, sex and development time on immune function in the cricket, Gryllus firmus. J Evol Biol. 19:834-843.

Rolff J. 2001. Effects of age and gender on immune function of dragonflies (Odonata, Lestidae) from a wild population. Can J Zool. 79:2176-2180.

Rolff J. 2002. Bateman's principle and immunity. Proc Biol Sci. 269:867-872.

Rolff J, van de Meutter F, Stoks R. 2004. Notes and comments time constraints decouple age and size at maturity and physiological traits. Am Nat. 164:559-565.

Rosenthal, R., Rosnow, RL. 1985. Contrast analysis: Focused comparisons in the analysis of variance. Cambridge: Press syndicate of the University of Cambridge.

Roth LM. 1948. A study of mosquito behavior. An experimental laboratory study of the sexual behavior of Aedes aegypti (Linnaeus). Am Midl Nat. 40:265-352.

Ryder JJ. 2007. Temporal dynamics of the encapsulation response towards a synthetic immune challenge in Acheta domesticus. Physiol Entomol. 32:240-245.

Sadd B, Holman L, Armitage H, Lock F, Marland R, Siva-Jothy MT. 2006. Modulation of sexual signalling by immune challenged male mealworm beetles (Tenebrio molitor, L.): Evidence for terminal investment and dishonesty. J Evol Biol. 19:321-325.

Sadd BM, Schmid-Hempel P. 2009. Principles of ecological immunology. Evol Appl. 2:113-121.

Schall JJ. 1982. Lizards infected with malaria: physiological and behavioral consequences. Science. 217:1057-1059.

Schmid-Hempel P. 2005. Evolutionary ecology of insect immune defenses. Annu Rev Entomol. 50:529-551.

Segoli M, Hoffmann AA, Lloyd J, Omodei GJ, Ritchie S a. 2014. The effect of virusblocking Wolbachia on male competitiveness of the dengue vector mosquito, Aedes aegypti. PLoS Negl Trop Dis. 8.12:e3294.

Sheldon B, Verhulst S. 1996. Ecological immunology: costly parasite defenses and tradeoffs in evolutionary ecology. Trends Ecol Evol. 11:317-321. 
Simmons LW. 2012. Resource allocation trade-off between sperm quality and immunity in the field cricket, Teleogryllus oceanicus. Behav Ecol. 23:168-173.

Siva-Jothy MT, Moret Y, Rolff J. 2005. Insect immunity: an evolutionary ecology perspective. Adv In Insect Phys. 32:1-48.

Stevens L, Yan G, Pray L. 1997. Consequences of inbreeding on invertebrate host susceptibility to parasitic infection. Evolution (N. Y). 51:2032-2039.

Vernick, Kenneth D. 1997. Mechanisms of immunity and refractoriness in insect vectors of eukaryotic parasites. In: Brey PT, Hultmark D, editors. Molecular mechanisms of immune responses in insects. 1st ed. London: Chapman \& Hall. p. 261-310.

Waite TA, Campbell LG. 2006. Controlling the false discovery rate and increasing statistical power in ecological studies. Ecoscience. 13:439-442.

Wigby S, Domanitskaya EV, Choffat Y, Kubli E, Chapman T. 2008. The effect of mating on immunity can be masked by experimental piercing in female Drosophila melanogaster. J Insect Physiol. 54:414-420.

Williams RW, Berger A. 1980. The relation of female polygamy to gonotrophic activity in the ROCK strain of Aedes aegypti. Mosq News 40.4: 597-604.

Wilson K, Cotter SC, Reeson AF, Pell JK, Cotteer SC. 2001. Melanization and disease resistance in insects. Ecol Lett. 4:637-649.

Wormington JD, Juliano SA. 2014. Sexually dimorphic body size and development time plasticity in Aedes mosquitoes (Diptera: Culicidae). Evol Ecol Res. 16:223-234.

Zuk M, Stoehr AM. 2002. Immune defense and host life history. Am Nat. 160.S4:S9S22. 


\section{TABLE}

Table 1.1. Multiple Contrasts of Behavioral Assays and Binary Mate Trials. Orthogonal and non-orthogonal ${ }^{1}$ contrasts test the effects of puncture and living or heat-killed bacteria inoculation on the probability of obtaining a mate in the male behavioral assay and binary mating trials. Multiple comparisons were corrected with the false discovery rate (FDR). Comparisons are significant if the uncorrected $P<$ Critical $P$ (FDR), and denoted by bold type and an asterisk.

\begin{tabular}{|c|c|c|c|c|c|c|}
\hline \multirow[b]{2}{*}{ Contrast } & \multirow[b]{2}{*}{ Hypothesis } & \multirow[b]{2}{*}{$P_{\text {critical }}$} & \multicolumn{2}{|c|}{ Behavioral Assay } & \multicolumn{2}{|c|}{ Binary Mating Trials } \\
\hline & & & $\chi^{2}{ }_{1}$ & $P_{\text {uncorrected }}$ & $\chi_{1}^{2}$ & $P_{\text {uncorrected }}$ \\
\hline $\begin{array}{l}\text { Naïve } v s . \\
\text { living } E \text {. } \\
\text { coli + heat- } \\
\text { killed } E \text {. } \\
\text { coli + sham }\end{array}$ & $\begin{array}{l}\text { The effect of } \\
\text { puncture vs. } \\
\text { none }\end{array}$ & 0.0125 & 0.47 & 0.4934 & 6.90 & 0.0086* \\
\hline $\begin{array}{l}{ }^{1} \text { Naïve } v s . \\
\text { sham }\end{array}$ & $\begin{array}{l}\text { The effect of } \\
\text { sterile } \\
\text { puncture vs. } \\
\text { none }\end{array}$ & 0.025 & 1.17 & 0.2801 & 4.18 & 0.0408 \\
\hline $\begin{array}{l}\text { Sham } v s . \\
\text { heat-killed } \\
\text { E. coli }+ \\
\text { living } E \text {. } \\
\text { coli }\end{array}$ & $\begin{array}{l}\text { The effect of } \\
\text { bacteria (live } \\
\text { or heat-killed) } \\
\text { vs. sterile } \\
\text { inoculation }\end{array}$ & 0.0375 & 0.86 & 0.353 & 0.59 & 0.4433 \\
\hline $\begin{array}{l}\text { Living } E \text {. } \\
\text { coli vs. } \\
\text { heat-killed } \\
\text { E. coli }\end{array}$ & $\begin{array}{l}\text { The effect of } \\
\text { living bacteria } \\
\text { vs. dead } \\
\text { bacteria }\end{array}$ & 0.05 & 2.27 & 0.1321 & 0.21 & 0.6455 \\
\hline
\end{tabular}




\section{FIGURES}

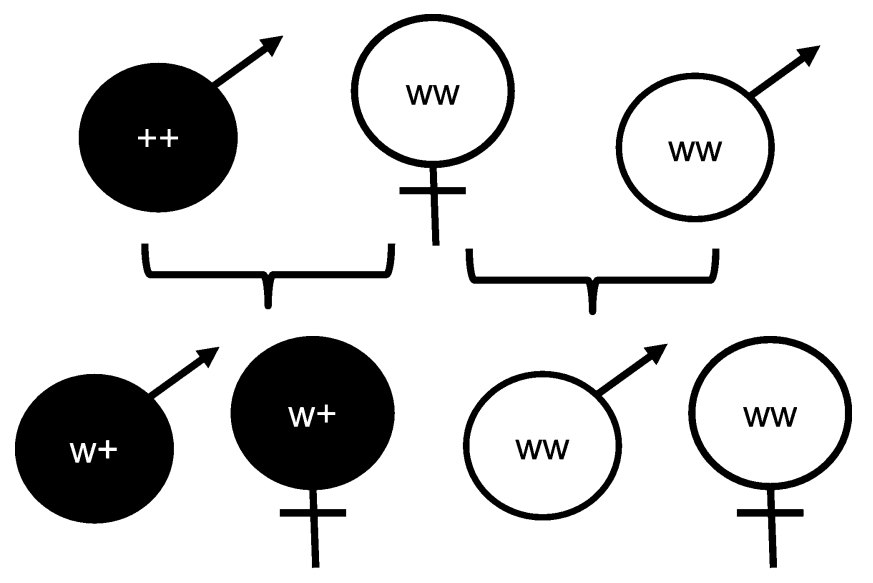

Figure 1.1. Inheritance of Wild-Type and White-Eyed Mutant Phenotypes. Phenotype is determined by a single recessive KHW mutant allele inherited with $100 \%$ penetrance (adapted from Clements 1995). All females in binary mating trials express white eyes (ww), and can mate with either a wild-type (++) or white-eyed (ww) mutant male. Mating with the wild-type male will produce wild-type phenotype (w+) in $100 \%$ of her offspring, and mating with the white-eyed mutant will result in $100 \%$ of her offspring having white eyes (ww). Dark circles represent black eyed phenotypes, while white circles represent the white-eyed phenotype. 

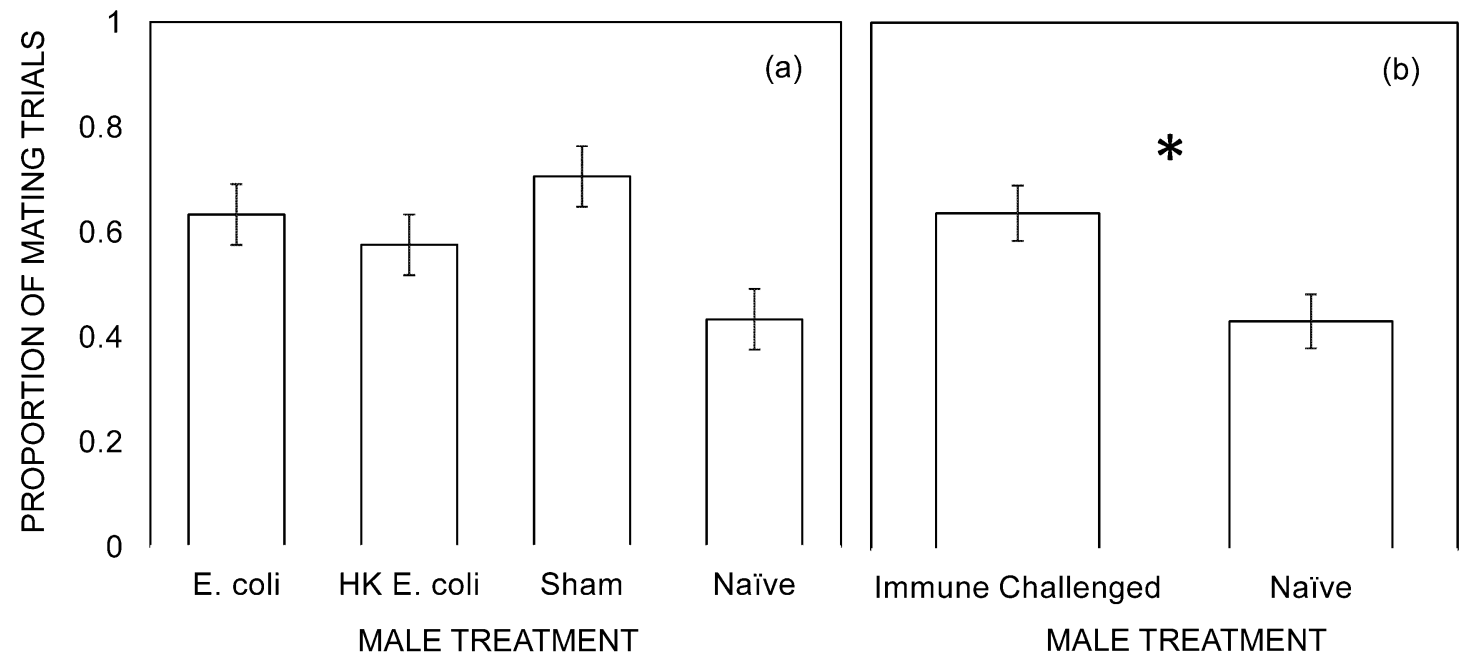

Figure 1.2. Proportion of Mating Trials Where a Male Successfully Sired Offspring. Least square mean \pm SE proportion of the proportion mating trials where a male successfully sired offspring for immune challenge treatment groups. (a) Males inoculated with three different immune challenges display marginally non-significant trends of higher mating success relative to naive control males (ANOVA, $\chi^{2}{ }_{3}=7.05, P=0.0703$ ). (b) When the immune challenged males are pooled into one category, they have significantly higher mating success relative to naïve control males (ANOVA, $\chi^{2}{ }_{1}=6.90$, $P=0.0086$ ). An asterisk between groups indicates a significant difference between immune challenged naïve controls, experimentwise $\alpha=0.05$. 

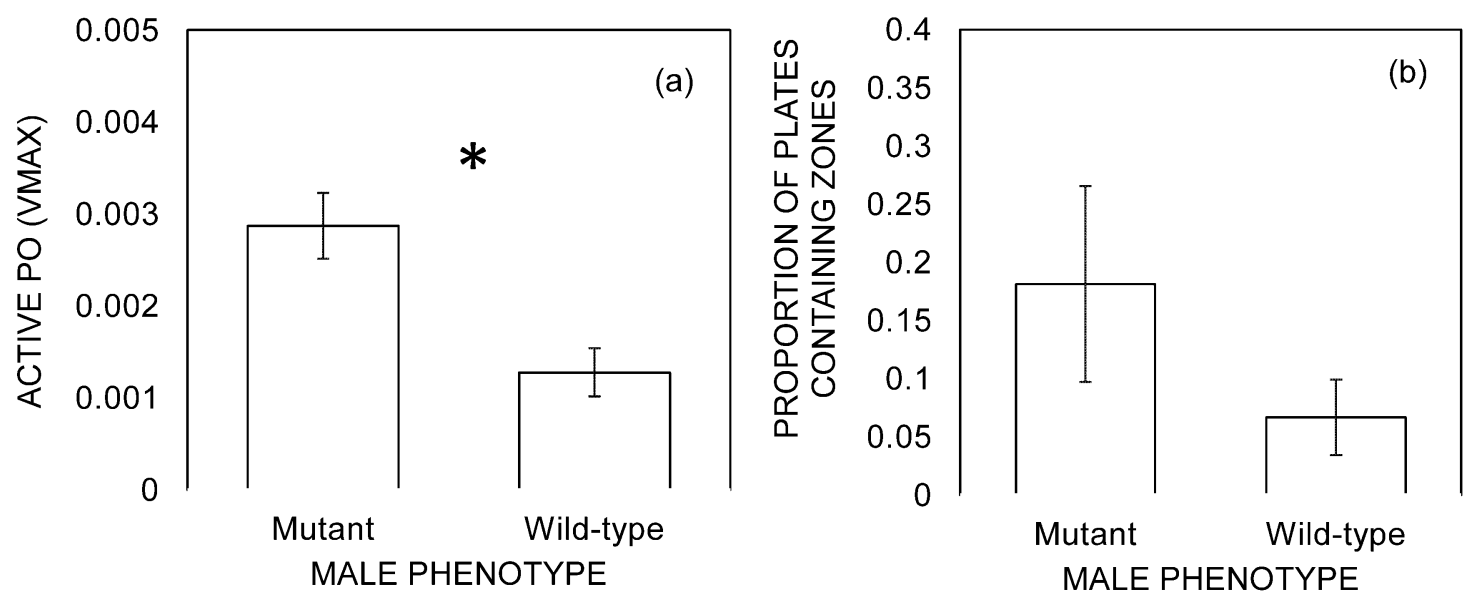

Figure 1.3. Measures of Innate Immunity for Male Phenotype. Active PO and proportion of plates containing zones are reported as least square means \pm SE. Within each panel, an asterisk indicates significantly different immune responses of mutant and wild-type males, experimentwise $\alpha=0.05$. (a) Mutant males had significantly (*) higher titers of active phenoloxidase relative to wild-type males (ANOVA, $F_{1,110}=12.73, P=0.0005$ ). (b) Though marginally non-significant, mutant male homogenates produced more zones of inhibition relative to wild type male homogenates (ANOVA, $\chi^{2}{ }_{1}=3.48, P=0.062$ ). 


\title{
CHAPTER II
}

\section{QUANTIFYING SEXUAL PERFORMANCE IN YELLOW FEVER MOSQUITOES (DIPTERA: CULICIDAE) USING EXOGENOUS MATING CUES AND RAPID TIME LAPSE PHOTOGRAPHY}

\begin{abstract}
Our understanding of mosquito mating behavior, though an important aspect of population management, is limited by a shortage of methods for quantifying individual mosquito sexual behavior. We describe the use of low cost digital cameras for behavioral assays that precisely measure rapid and frequent sexual behaviors of individual mosquitoes using time lapse video recording. These mating trials simulate natural breeding conditions in which mating cues such as pheromone emission and swarming behavior of conspecifics, as well as host cues are present and influence the mating behaviors in focal individuals. Such cues have been scarce or nonexistent in previous mosquito mating studies. We found that male Aedes aegypti mating behaviors are highly variable, and that few individuals succeed in obtaining mates, while most are unsuccessful despite the presence of some mating-related behavior. Approximately $95 \%$ of males yielded quantitative behavioral data, regardless of their ultimate mating success. We offer suggestions on improving this technique, as well as supplementary post hoc assays to get a comprehensive indication of male sexual competence.
\end{abstract}




\section{Keywords}

Flying, grasping, approaching, latency, SIT, RIDL

\section{Introduction}

Mosquito mating behavior is of potentially great medical and economic importance. Some current control strategies seek to reduce populations and disease transmission through the release or of modified mosquitoes, such as Sterile Insect Technique (SIT), Release of Insects with Dominant Lethal alleles (RIDL), and transgenic females with altered susceptibility to pathogens (Irvin et al. 2004; Helinski et al. 2006; Alphey et al. 2010; Oliva et al 2013). The success of these strategies depends on the sexual performance of the released males relative to wild males, or on receptivity of released females. Despite this, at least in SIT, radiation treatments hinder male reproductive success (Helinski et al. 2006; Oliva et al. 2013). If transgenic females suffer from low reproductive success due to lack of mating they will fail to become established in wild populations (Irvin et al. 2004). Consequently, detailed understanding of mating behavior can be vital for successful control (Helinski et al. 2006; Helinski et al. 2009; Bargielowski et al. 2011; 2013; Segoli et al. 2014). Beyond this practical consideration, the role of sexual selection in mosquito populations is a fundamentally interesting topic in its own right (Ponlawat and Harrington 2007; Ponlawat and Harrington 2009; Cator et al. 2009; Cator et al. 2011; Cator and Harrington 2011; Helinski and Harrington 2012; Helinski et al. 2012b) that merits further experimentation.

Existing approaches to investigating mosquito mating behavior have distinct limitations. Audio recordings of wing beat frequencies only quantify one aspect of 
reproductive investment, and quantifying this for many individuals simultaneously may be problematic for the audio software that detects harmonic frequencies (SK Sakaluk, personal communication). Visual surveillance of individuals yield low throughput data, and observing individuals in swarms is problematic due to the high risk of human error when following small, rapidly-moving focal individuals in swarms. In addition, it is difficult to induce mating in a short period of time in the controlled laboratory setting, perhaps because natural cues that mosquitoes would perceive in the field, such as pheromones, swarming conspecifics, and host cues that stimulate mating behavior, are absent (Cabrera and Jaffe 2007). The use of males with phenotypically obvious mutations that are expressed in their offspring, or the use of males with isotope or fluorescent labeled semen may be informative and practical if the principal objective of the study is to determine insemination success. This technique does not yield quantification of the differences in behavior between successful and unsuccessful males.

The purpose of this paper is to describe methods for behavioral assays of mating behavior that were developed while studying terminal investment in Aedes aegypti (Schumacher et al 2015, in review). We describe behavioral mating assays that use lowcost digital cameras to quantify behavior of focal individuals that receive exogenous mating cues from a swarm of individuals that help to stimulate mating behaviors. We used rapid time lapse video recording so that observations can be tallied rather than timed to obtain precise behavioral measurements of mating-related behaviors that are brief and numerous. These behaviors include several measurements of harassment and persistence, confirmation of copulation and insemination, as well as flying (a swarming behavior that 
requires males that are capable of high levels of exertion). These behavioral assays provide high throughput data relative to visual surveillance methods, and are ideal for studies that aim to quantify and to compare general mating behaviors of individual mosquitoes or other swarming insects.

\section{Methods}

\section{Study Organism}

We quantified the mating behaviors of Aedes aegypti. This species is easy to rear in the laboratory and willingly mates in small containers, but equally important, $A$. aegypti is a major disease vector that is often the target of SIT and RIDL population control because of its medical importance as a vector of dengue virus (Alphey et al. 2010; Alphey et al. 2013; Segoli et al. 2014). Mating behavior typically occurs in the presence of a blood-meal host. Males release aggregation pheromones in the presence of this host, attracting both females and males, creating a 3 dimensional lek in the form of a swarm (Cabrera and Jaffe 2007). Females enter the swarm where they are approached by one or more males, and it is common for several males to grasp a single female at once (Christophers 1960). Swarming is energetically expensive for a male (Yuval et al. 1994), and though it increases the probability of copulation, a swarm is not necessary for mating to occur (Oliva et al. 2014) and males will also attempt to mate with resting females (Christophers 1960). Male- female pair forming occurs when they acoustically match their wing beat frequencies, a potential mate choice mechanism known as harmonic convergence (Cator et al. 2009). Because of their relatively larger size and ability to decline harmonic convergence, females are ultimately the choosey sex and often reject 
grasping males (Cabrera and Jaffe 2007; Ponlawat and Harrington 2009; Cator and Harrington 2011). Copulation and insemination lasts an average of only 10 seconds (Roth 1948; Ponlawat and Harrington 2009), and males transfer accessory gland protein secretions in their ejaculate that act as a long-term post copulatory mating barrier, making females refractory to mating for one or more gonotrophic cycles, (Craig 1967; LimaCamara et al. 2013) while also increasing host seeking and oviposition behavior (Sirot et al. 2008; Ponlawat and Harrington 2009). Multiple matings are not necessary for females because a female can store sperm indefinitely in her 3 sperm storage organs (spermatheca), though multiple paternity does occur at low frequencies (10-15\%) in Aedes (Boyer et al. 2012; Helinski and Harrington 2012).

\section{Animal Husbandry}

Mosquito larval environments are likely to influence the sexual competitiveness and mating behavior of male and female mosquitoes. Better fed and less crowded larval environments result in larger mosquitoes, and larger males have higher mating success (Ponlawat and Harrington 2009), possibly because of their ability to attract females through increased resource reserves that impact flight and courting ability. Larger females have higher reproductive success, and are better able to thwart males, though it is also possible that assortative mating based on size can influence male mating success (Cabrera and Jaffe 2007). A full description of our larval rearing environments was provided by Schumacher et al. (2015, in review).

For controlled mating trials, it is critical to ensure adult virginity because of the lasting effects of accessory gland protein on females. To obtain adult virgins, larvae were 
allowed to develop collectively in a $1 \mathrm{~L}$ plastic container, then separated after pupation into individual $15 \mathrm{~mL}$ glass vials $(21 \times 70 \mathrm{~mm})$. Vials were covered with a fine mesh, secured with a rubber band and queued on a vial rack. Water was removed from the vials as adults eclosed, and a sucrose (1:5 sucrose:reverse osmosis water) dipped cotton roll was placed across vials, and remoistened every other day to prevent desiccation of cotton pads. Mosquitoes were housed in benign conditions $\left(28^{\circ} \mathrm{C}, 60 \%\right.$ relative humidity, $14: 10$ $\mathrm{h}$ light:dark photoperiod) until ready for behavioral assays. Adult male mosquitoes are not physically prepared for reproduction until their terminal abdominal segments rotate $180^{\circ}$, which may take $24-48 \mathrm{~h}$ after adult emergence (Roth 1948), though this time may vary among species. Females are capable of mating immediately after emergence, though newly emerged females are not as attractive to males relative to older females (Roth 1948). Therefore, behavioral assays began after males and females were $>48 \mathrm{~h}$ old.

\section{Behavioral Assay Materials and Methods}

A colony cage containing several hundred A. aegypti was used to provide mating cues from swarming and pheromones to the focal males. The colony cage was a screened cube $60 \mathrm{~cm}$ on each side with a wooden frame and a $60 \times 20 \mathrm{~cm}$ opening at the bottom front of the cage covered with a cloth sleeve for mosquito transfer (Figure 2.1). Mosquitoes were reared and maintained for this colony so that small groups from 1-2 days of adult eclosion were added as cohorts on the days in which behavioral assays occurred. Thus, the colony always contained a new group of females to stimulate colony and focal male mating behavior. 
Mating arenas were $300 \mathrm{~mL}$ Solo paper cups (CDC Janitor/Paper Supply catalog \#410W height x diameter: $8.5 \times 8.5 \mathrm{~cm})$. A $\sim 15 \times 15 \mathrm{~cm}$ sheet of clear Plexiglas ${ }^{\circledR}$ was taped to the opening of the cup to provide a clear view for video recording. The bottoms of the cups were replaced with fine ( 625 holes per square inch) mosquito mesh so that the mosquitoes in the cup were exposed to adequate airflow and auditory and pheromone cues from the colony during the mating trials, and to prevent condensation on the Plexiglas. A $\sim 2 \mathrm{~cm}$ hole for mosquito transfer by aspiration was cut in the side of the cup and covered with tape.

Individuals were acclimated to the environment in which they were tested prior to observation. Because males were the focal subject in our study, we acclimated single males in their respective mating arenas for $1 \mathrm{hr}$, whereas we acclimated females individually in the screened glass vials in which they had eclosed. The environment in which we recorded behavior was: $27{ }^{\circ} \mathrm{C}, 20 \%$ relative humidity. Behavioral assays were staggered so that while the first group of three mating trials was video recorded, a second group of 3 mating trials was acclimating to the environment.

We used Go Pro Hero ${ }^{\circledR} 3$ (Woodman Labs Inc. ()) cameras because they are known for their ability to connect to mobile devices via Wi-Fi for easy operating and monitoring, free editing software, lightweight and miniature size facilitating multiple cameras to fit in a small recording space, shock-and water-proof features, and affordable supplementary batteries. Other mountable time lapse digital cameras likely could be used. Our behavioral assays used 3 cameras simultaneously for video recording. Because camera and mating arena orientation must be precise, and focal mosquitoes may initiate 
mating behaviors immediately upon introduction of the female, the cameras and mating arenas were afixed onto a 42 x $35 \mathrm{~cm}$ plastic "stage" using hook-and-loop fasteners prior to female introduction into the arena. With the 3 cameras and 3 arenas secured to the stage (Figure 2.1) and an acclimated male occupying each arena, we began recording, then added females to the arenas by holding the vial to the $2 \mathrm{~cm}$ opening and allowing the female to fly in. Once all three females were added to their respective arenas, the entire stage was transferred into the colony box (Figure 2.1) containing a swarm of mosquitoes (see supplementary video). Aedes aegypti copulation is often stimulated after they have been disturbed and take flight (Christophers 1960), and previous mating studies have been performed by disturbing cages to induce mating (Williams and Berger 1980). We provided a continuous, but gentle disturbance for the colony and focal males using an oscillating tower fan (Wexford®, low speed/oscillation) placed behind the colony box and facing the mesh-covered end of the arenas for the entirety of the behavioral assay. Because A. aegypti are attracted to carboxylic acids found in foot odors (Owino et al. $2014 ; 2015)$, and males and females become sexually active when a host cue is present (Christophers 1960; Cabrera and Jaffe 2007), unwashed socks (worn the day before and sealed in a plastic bag) were placed in the colony box with the mating arenas (Figure 2.1) to stimulate host seeking and mating behaviors of males and females in the colony and arenas.

Our behavioral assays were recorded for $\sim 1 \mathrm{~h}$, though exact timing depended on camera battery life and data storage. To avoid manually timing behaviors with a stop watch and to obtain the most accurate observations, videos were recorded with wide 
angle time lapse photography ( 1 photograph every $2 \mathrm{sec}$ ) so that the exact number of frames per behavior could be quantified and converted to time (e.g., 10 frames flying x 2 $\mathrm{s}$ per frame $=20 \mathrm{~s}$ flying). We chose a standard sampling unit for all mating trials, where the trials of the first 1200 frames ( $40 \mathrm{~min}$ ) after the female entered the mating arena were observed for data collection. Several trials had slightly fewer frames (by $<20$ frames, or 40 s). Any videos that were fewer than < 1180 frames (e.g., due to battery failure) were not considered for quantifying behavior.

Observable mating behaviors were quantified after all videos were recorded (Table 2.1). To be confident in our visual assessment of male mating success and female insemination (Figure 2.2), we dissected females and examined spermathecae under 100X oil immersion magnification to confirm presence of sperm (for a review of A. aegypti spermatheca dissection, see Benedict 2014) (Figure 2.3). Latency measurements were censored if that particular behavior did not occur in the 40 minute trial period and recorded as the maximal number of frames in the video (1180-1200 frames). Males and females were separated immediately following mating trial termination to decrease the probability of insemination after the time allotted for mating trials. Mating arenas were wiped down with $95 \%$ ethanol between uses in an effort to remove any chemical cues that may have been deposited during the trial.

\section{Results}

With the use of an extra battery for each camera, we were able to complete up to 5 series of mating trials each day (15 trials total). Batteries had to be replaced after the first 2 series of trials and recharged while other batteries were used. We video recorded 110 
behavioral assays, though 9 assays were not considered because the standard sampling unit of 1180-1200 photographs was not obtained due to battery failure.

Out of 103 behavioral assays that were considered, 99 trials included males that had flight activity. The time males devoted to flying during the trial period was highly variable (Table 2.1). Two different lighting regimes were used because of malfunction of room fluorescent lights for several days. During this time, we illuminated the room with an incandescent desk lamp, which increased the time males spent flying (ANOVA, F2,97 $=7.40, P=0.0010$ ), but did not affect any other measurement of sexual behavior.

Of 103 trials, 40 involved males approaching females in an apparent attempt to mate. Among these males, mating attempts ranged from 1 to 9 times, and the amount of time these males spent harassing females was highly variable (Table 2.1). Measurements on latency to initial contact, or the male's first approach to the female, were obtained for all trials. Of these, 40 males were uncensored, and the range of observed values was, again, broad (Table 2.1).

Out of the 40 trials where males courted females, 15 males successfully mated at least once, and 2 males successfully mated (as determined by face-to-face orientation and clasping of genitalia, Figure 2.2) 2-3 times in a single trial. We recorded 4 mating trials where copulation was not visible, though sperm was present in the female's spermathecae (Figure 2.3). All of the females in this study were virgins, and it is likely that disturbance of the arena at termination of the mating trial stimulated flying and mating (i.e., before the male and female were separated, but after video recording terminated). Because copulation was not observed in the time allotted for the behavioral assay, we did not 
count these individuals as "mated" in our data set. Time to a successful mating event also varied considerably (Table 2.1).

We found a significant random effect of block (i.e., temporally separated batches

of larvae from individual larval rearing containers) in both latency to initial approach and latency to successful mating events (Wald $\chi^{2}=0.000, P=<0.0001$ ), but this effect was not evident in any other sexual behavior.

\section{Discussion}

Mating behaviors from this study were highly variable, and sexual competence was likely influenced by factors other than artificial laboratory conditions. The males in our study were manipulated with four treatments for a separate study (Schumacher et al 2015, in review), including inoculation via a puncture with: a living bacterium; heatkilled bacteria as an immune stimulator; a sterile puncture (a sham control); and a naïve (unmanipulated) control. Energetically demanding behaviors such as flying and female harassment largely depend on resource reserves available to males. Nutritional reserves will be affected by the larval crowding and feeding regimen (Christophers 1960) and significant life history events, such as a pathogenic infection, that might divert resources away from reproduction and toward immunity (Sheldon and Verhulst 1996; Hurd 2001; Zuk and Stoehr 2002; Jacot et al. 2004; Ahmed and Hurd 2006; Lawniczak et al. 2007). The time of day at which behavioral trials were done may affect mating behaviors as well. For example, our behavioral assays were all performed mid-morning to late afternoon, though they may have been more successful if they occurred just after sunrise 
or before sunset when A. aegypti are typically the most active (Hartberg 1971; Oliva et al. 2014).

Only $\sim 4 \%$ of the males in our assays showed no observable sexual behavior, though approximately $15 \%$ of our total behavioral assays (or $38 \%$ of all males that approached females) resulted in a successful mating attempt. We did not expect the majority of males to mate successfully because: 1) Mating success is generally more variable for males than for females (Trivers 1972), 2) Female mosquitoes can be choosey, selecting only a small minority of sexually attractive males, leaving the majority of males unsuccessful at attracting females, 3) Females in these assays were exposed to sexual signals from many conspecifics, which would predict a higher degree of choosiness if the chance of encountering a higher quality male is high (Johnstone et al. 1995), and 4) Predation risk is high in mosquito swarms (Yuval and Bouskila 1993), and females may benefit by waiting to mate with the most attractive male, storing his sperm indefinitely, and forgoing future mating opportunities (Yuval and Fritz 1994). Few males within mosquito populations mate several times, and many males may never mate (for a review, see Yuval et al. 1993). This pattern was evident in our mating trials: many males grasped females multiple times (40 trials) though only $38 \%$ of the males that attempted to mate were eventually accepted by a female. In addition, several males were able to mate with a single female 2-3 times, though we do not know the extent of sperm and accessory gland protein transfer within each of these successful matings beyond the fact that females stored sperm from at least one of these matings. 
Supplementary information could be added to behavioral assays to achieve better measures of male sexual behavior without hindering the video assays. Post hoc assays could be performed after behavioral trials, such as spermatheca (Ponlawat and Harrington 2009) or testes (Ponlawat and Harrington 2007) sperm counts, degree of female refractoriness influenced by male accessory gland proteins (Helinski et al. 2012a), and sperm depletion rates (Radhakrishnan et al. 2009). Male and female size can be important in sexual behavior, though we were unable to test for this in our data set. To obtain longevity data that were necessary for our study, we allowed male and female mosquitoes to live until they died naturally, and because their wings become damaged and unmeasurable with age, we only had wing length data for those that died young (approximately $48 \%$ of the data set). Because we reared our mosquitoes in favorable conditions, size did not vary substantially (mean $\pm \mathrm{SD}=2.03 \pm 0.07 \mathrm{~mm}$ ), and as a result of low wing length variation, we found that wing length did not improve our statistical model, as determined by Akaike information criterion (AICc) in SAS 9.3. We thus omitted wing length in our analysis, though we suggest that in future studies mosquitoes be killed and measured immediately after behavioral trials (especially if wing length is potentially variable, as is the case for crowded or otherwise stressful larval environments) or obtaining some other measure of size (e.g., dry mass).

Our behavioral assays were designed for A. aegypti, a vector mosquito that has very simple rearing requirements in the laboratory. These methods could be readily adapted for other Aedes mosquitoes such as Aedes albopictus, or other insects with similar mating biology and behavior (i.e., mating in swarms or other leks involving 
aggregation pheromones: e.g., midges, black flies, robber flies, dance flies, mayflies, and ants; for a more complete list see Downes (1969) and Sullivan (1981)). We believe these video techniques could be adapted to suit species that are more difficult to rear, or have different mating cues and behaviors. Though we measured male mating success, females could be scored for similar behaviors, such as whether she immediately accepts the initial mating attempt, how many mating attempts she experiences before she accepts a mate, and whether or not she instigates the mating attempt. Given the considerable amount of research on mosquito mating behavior and the relatively few attempts to quantify individual male behavior, the approach we took using multiple, small, digital cameras and replicate mating arenas housed within a larger swarm cage should prove useful. The ability to quantify sexual behavior in these males is vital for understanding and improving male sexual performance, in the context of release modified males (SIT, RIDL) for mosquito control. 


\section{REFERENCES}

Ahmed AM, Hurd H (2006) Immune stimulation and malaria infection impose reproductive costs in Anopheles gambiae via follicular apoptosis. Microbes Infect 8:308-315. doi: 10.1016/j.micinf.2005.06.026

Alphey L, Benedict M, Bellini R, et al (2010) Sterile-insect methods for control of mosquito-borne diseases: an analysis. Vector Borne Zoonotic Dis 10:295-311. dio: $10.1089=$ vbz.2009.0014

Alphey L, McKemey A, Nimmo D, et al (2013) Genetic control of Aedes mosquitoes. Pathog Glob Health 107:170-179. doi: 10.1179/2047773213Y.0000000095

Bargielowski I, Nimmo D, Alphey L, Koella JC (2011) Comparison of life history characteristics of the genetically modified OX513A line and a wild type strain of Aedes aegypti. PLoS One 6:e20699. doi: 10.1371/journal.pone.0020699

Benedict MQ (2014) Dissecting spermathecae to determine insemination status. Benedict M (ed) Methods in Anopheles Research, 4th edn. Malaria Research and Reference Reagent Resource Center, Atlanta, GA, pp 1-2

Boyer S, Toty C, Jacquet M, et al (2012) Evidence of multiple inseminations in the field of Aedes albopictus. PLoS One 7:e42040. doi: 10.1371/journal.pone.0042040

Cabrera M, Jaffe K (2007) An aggregation pheromone modulates lekking behavior in the vector mosquito Aedes aegypti (Diptera: Culicidae). J Am Mosq Control Assoc 23:1-10. doi: 10.2987/8756-971X(2007)23[1:AAPMLB]2.0.CO;2

Cator LJ, Arthur BJ, Harrington LC, Hoy RR (2009) Harmonic convergence in the love songs of the dengue vector mosquito. Science 323:1077-1079. doi:

10.1126/science. 1166541

Cator LJ, Arthur BJ, Ponlawat A, Harrington LC (2011) Behavioral observations and sound recordings of free-flight mating swarms of Ae. Aegypti (Diptera: Culicidae) in Thailand. J Med Entomol 48:941-946. doi: 10.1603/ME11019

Cator LJ, Harrington LC (2011) The harmonic convergence of fathers predicts the mating success of sons in Aedes aegypti. Anim Behav 82:627-633. doi: 10.1016/j.anbehav.2011.07.013 
Christophers SR (1960) Aedes aegypti (L.) the yellow ferver mosquito: Its life history, bionomics and structure. The Syndics of the Cambridge University Press, London

Craig GB (1967) Mosquitoes: female monogamy induced by male accessory gland substance. Science (80- ) 156:1499-1501. doi: 10.1126/science.156.3781.1499

Downes JA (1969) The swarming and mating fight of Diptera. Annu Rev Entomol 14:271-298. doi: 10.1146/annurev.en.14.010169.001415

Hartberg WK (1971) Observations on the mating behaviour of Aedes aegypti in nature. Bull World Health Organ 45:847-850.

Helinski MEH, Deewatthanawong P, Sirot LK, et al (2012a) Duration and dosedependency of female sexual receptivity responses to seminal fluid proteins in Aedes albopictus and Ae. aegypti mosquitoes. J Insect Physiol 58:1307-1313. doi: 10.1016/j.jinsphys.2012.07.003

Helinski MEH, Harrington LC (2012) The role of male harassment on female fitness for the dengue vector mosquito Aedes aegypti. Behav Ecol Sociobiol 66:1131-1140. doi: $10.1007 / \mathrm{s} 00265-012-1365-9$

Helinski MEH, Parker AG, Knols BGJ (2006) Radiation-induced sterility for pupal and adult stages of the malaria mosquito Anopheles arabiensis. Malar J 5:41. doi: $10.1186 / 1475-2875-5-41$

Helinski MEH, Parker AG, Knols BGJ (2009) Radiation biology of mosquitoes. Malar J 8 Suppl 2:S6. doi: 10.1186/1475-2875-8-S2-S6

Helinski MEH, Valerio L, Facchinelli L, et al (2012b) Evidence of polyandry for Aedes aegypti in semifield enclosures. Am J Trop Med Hyg 86:635-641. doi: 10.4269/ajtmh.2012.11-0225

Hurd H (2001) Host fecundity reduction: A strategy for damage limitation? Trends Parasitol 17:363-368. doi: 10.1016/S1471-4922(01)01927-4

Irvin N, Hoddle MS, O'Brochta DA, et al (2004) Assessing fitness costs for transgenic Aedes aegypti expressing the GFP marker and transposase genes. Proc Natl Acad Sci USA 101:891-896. doi: 10.1073/pnas.0305511101

Jacot A, Scheuber H, Brinkhof MWG (2004) Costs of an induced immune response on sexual display and longevity in field crickets. Evolution 58:2280-2286. doi: 10.1554/03-660

Johnstone, RA, Reynolds, JD, Deutsch, JC (1995) Mutual mate choice and sex differences in choosiness. Evolution. 50:1382-1391.

Lawniczak MKN, Barnes AI, Linklater JR, et al (2007) Mating and immunity in invertebrates. Trends Ecol Evol 22:48-55. doi: 10.1016/j.tree.2006.09.012 
Lima-Camara TN, Codeço CT, Honório NA, et al (2013) Male accessory gland substances from Aedes albopictus affect the locomotor activity of Aedes aegypti females. Mem Inst Oswaldo Cruz 108 Suppl :18-25. doi: 10.1590/00740276130381

Oliva CF, Damiens D, Benedict MQ (2014) Male reproductive biology of Aedes mosquitoes. Acta Trop 132:1-8. doi: 10.1016/j.actatropica.2013.11.021

Oliva CF, Damiens D, Vreysen MJB, et al (2013) Reproductive strategies of Aedes albopictus (Diptera: Culicidae) and implications for the sterile insect technique. PLoS One. doi: 10.1371/journal.pone.0078884

Owino EA, Sang R, Sole CL, et al (2014) Field evaluation of natural human odours and the biogent-synthetic lure in trapping Aedes aegypti, vector of dengue and chikungunya viruses in Kenya. Parasit Vectors 7:451. doi: 10.1186/1756-3305-7451

Owino EA, Sang R, Sole CL, et al (2015) An improved odor bait for monitoring populations of Aedes aegypti-vectors of dengue and chikungunya viruses in Kenya. Parasit Vectors 8:1-12. doi: 10.1186/s13071-015-0866-6

Ponlawat A, Harrington LC (2007) Age and body size influence male sperm capacity of the dengue vector Aedes aegypti (Diptera: Culicidae). J Med Entomol 44:422426. doi: 10.1603/0022-2585(2007)44[422:AABSIM]2.0.CO;2

Ponlawat A, Harrington LC (2009) Factors associated with male mating success of the dengue vector mosquito, Aedes aegypti. Am J Trop Med Hyg 80:395-400.

Radhakrishnan P, Pérez-Staples D, Weldon CW, Taylor PW (2009) Multiple mating and sperm depletion in male Queensland fruit flies: effects on female remating behaviour. Anim Behav 78:839-846. doi: 10.1016/j.anbehav.2009.07.002

Roth LM (1948) A study of mosquito behavior. An experimental laboratory study of the sexual behavior of Aedes aegypti (Linnaeus). Am Midl Nat 40:265-352. doi: 10.1674/0003-0031(2001)146

Segoli M, Hoffmann AA, Lloyd J, et al (2014) The effect of virus-blocking Wolbachia on male competitiveness of the dengue vector mosquito, Aedes aegypti. PLoS Negl Trop Dis 8:e3294. doi: 10.1371/journal.pntd.0003294

Sheldon B, Verhulst S (1996) Ecological immunology: costly parasite defenses and tradeoffs in evolutionary ecology. Trends Ecol Evol 11:317-321.

Sirot LK, Poulson RL, Mckenna MC, et al (2008) Identity and transfer of male reproductive gland proteins of the dengue vector mosquito, Aedes aegypti: potential tools for control of female feeding and reproduction. Insect Biochem 38:176-189. doi: 10.1016/j.ibmb.2007.10.007.Identity 
Sullivan RT (1981) Insect swarming and mating. Florida Entomol 64:44-65.

Trivers RL (1972) Parental investment and sexual selection. In: Campbell B (ed) Sexual selection and the descent of man 1871-1971. Aldine Publishing Company, Chicago, pp 136-179

Williams RW, Berger A (1980) The relation of female polygamy to gonotrophic activity in the ROCK strain of Aedes aegypti. Mosq. News 40:597-604

Yuval B, Bouskila A (1993) Temporal dynamics of mating and predation in mosquito swarms. Oeco 95:65-69.

Yuval B, Fritz GN (1994) Multiple mating in female mosquitoes-evidence from a field population of Anopheles freeborni (Diptera: Culicidae). Bull Entomol Res 84:137. doi: 10.1017/S0007485300032326

Yuval B, Holliday-Hanson ML, Washing RK (1994) Energy budget of swarming male mosquitoes. Ecol Entomol 19:74-78.

Yuval B, Wekesa JW, Washino RK (1993) Effect of body size on swarming behavior and mating success of male Anopheles freeborni (Diptera:Culicidae). J Insect Behav $6: 333-342$.

Zuk M, Stoehr AM (2002) Immune defense and host life history. Am Nat 160 Suppl :S9S22. doi: $10.1086 / 342131$ 


\section{TABLE}

Table 2.1. Male Aedes aegypti Mating Behaviors. Mating behaviors were quantified using rapid time lapse behavioral assays. Within behavioral assays, individual frames were tallied and converted to time. The percentage of males (total $n=103$ ) that performed a given behavior is reported as performance. Mean \pm SD and range was calculated among males that performed the behavior

\begin{tabular}{|c|c|c|c|c|}
\hline Male behavior & Performance $(\%)$ & Measurement (unit) & Mean \pm SD & Range \\
\hline Swarming/Flying & 96.11 & Time spent flying (s) & $\begin{array}{c}72.67 \pm \\
102.92\end{array}$ & $2-690$ \\
\hline \multirow[t]{3}{*}{$\begin{array}{l}\text { Harassment/ } \\
\text { Persistence }\end{array}$} & 38.83 & $\begin{array}{l}\text { Times male } \\
\text { approaches female } \\
\text { (number) }\end{array}$ & $\begin{array}{c}2.55 \pm \\
2.18\end{array}$ & $1-9$ \\
\hline & & $\begin{array}{l}\text { Time spent grasping } \\
\text { / in physical contact } \\
\text { with female (s) }\end{array}$ & $\begin{array}{l}75.3 \pm \\
63.89\end{array}$ & $2-274$ \\
\hline & & $\begin{array}{l}\text { Latency to first } \\
\text { approach event (s) }\end{array}$ & $\begin{array}{c}325.65 \pm \\
420.80\end{array}$ & $2-1472$ \\
\hline \multirow[t]{2}{*}{$\begin{array}{l}\text { Successful } \\
\text { mating }\end{array}$} & 14.56 & $\begin{array}{l}\text { Face-to-face } \\
\text { orientation and } \\
\text { physical contact of } \\
\text { genitalia (yes/no) }\end{array}$ & - & - \\
\hline & & $\begin{array}{l}\text { Latency to } \\
\text { successful mating } \\
\text { event (s) }\end{array}$ & $\begin{array}{c}582.13 \pm \\
659.32\end{array}$ & $12-2084$ \\
\hline
\end{tabular}




\section{FIGURES}
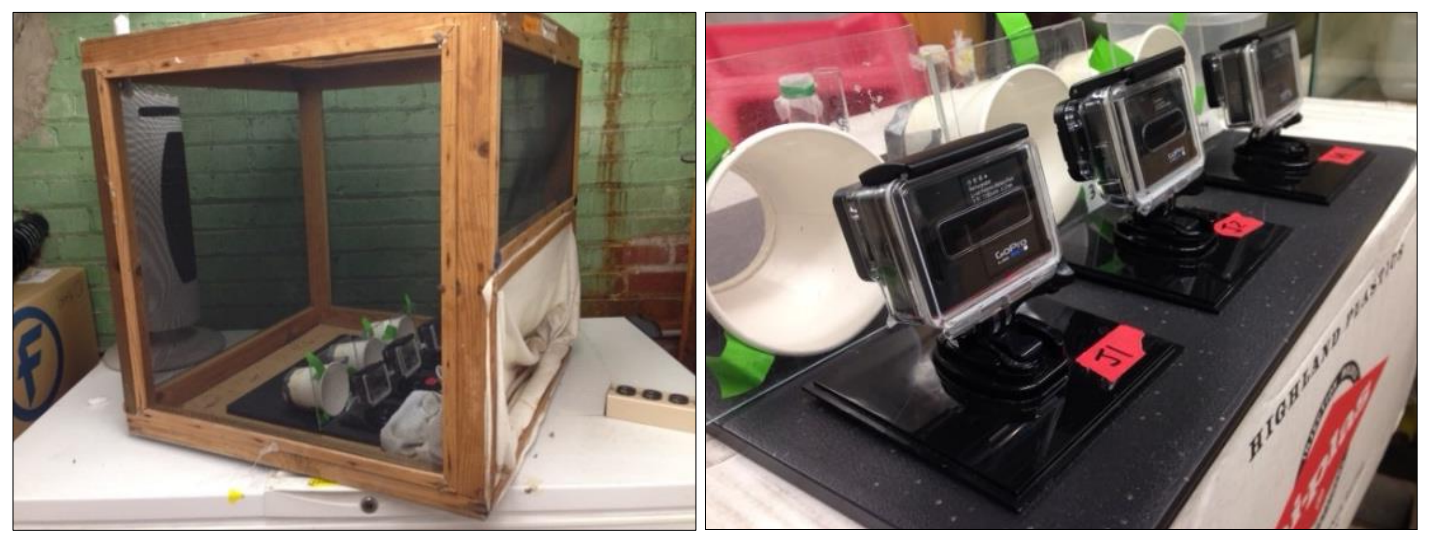

Figure 2.1. Materials and Methods of Behavioral Assays. Mating trials in a $60 \mathrm{~cm}^{3}$ cage containing a colony of mosquitoes, a tower fan and a pair of socks to stimulate mating behaviors (left). Three mating arenas and 3 cameras secured with hook-and-loop fasteners to a plastic cutting board for ease of transfer to the colony cage (right). 

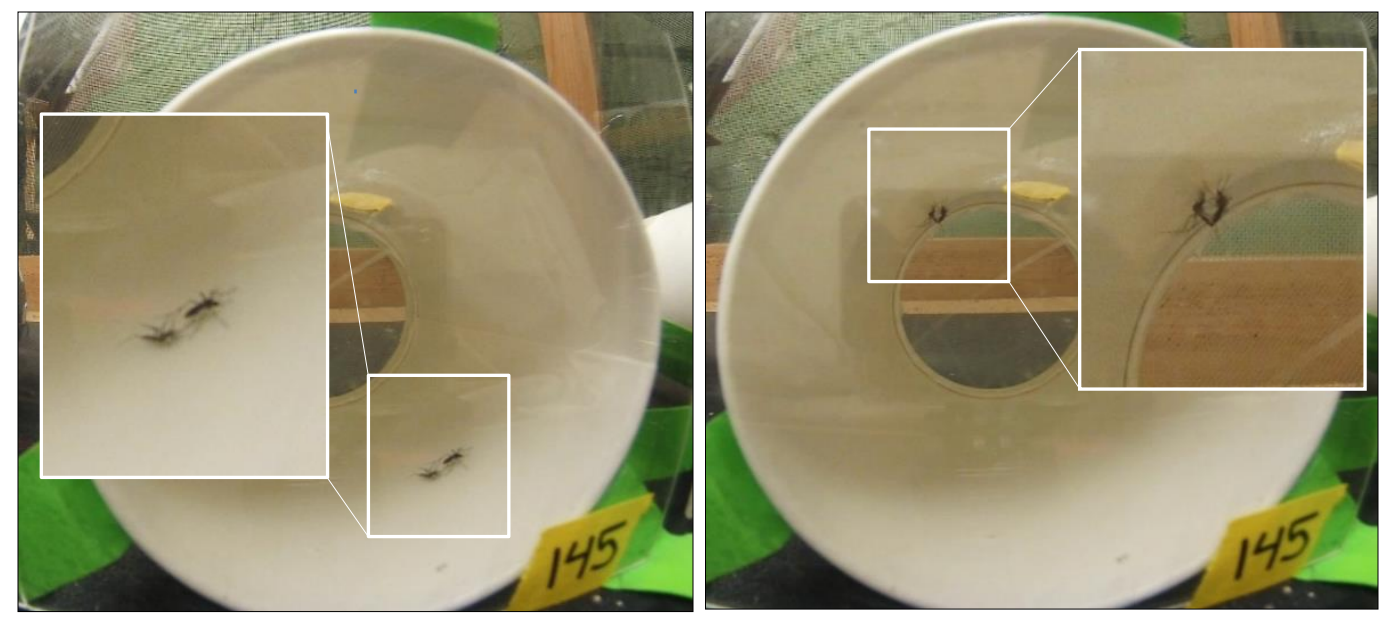

Figure 2.2. Observable Behaviors of Male and Female A. aegypti. Males approach females and harass them through persistent physical contact, though may not successfully mate (left). In successful mating attempts, males and females are oriented face-to-face, and their genitalia are in physical contact for sperm transfer (right). 

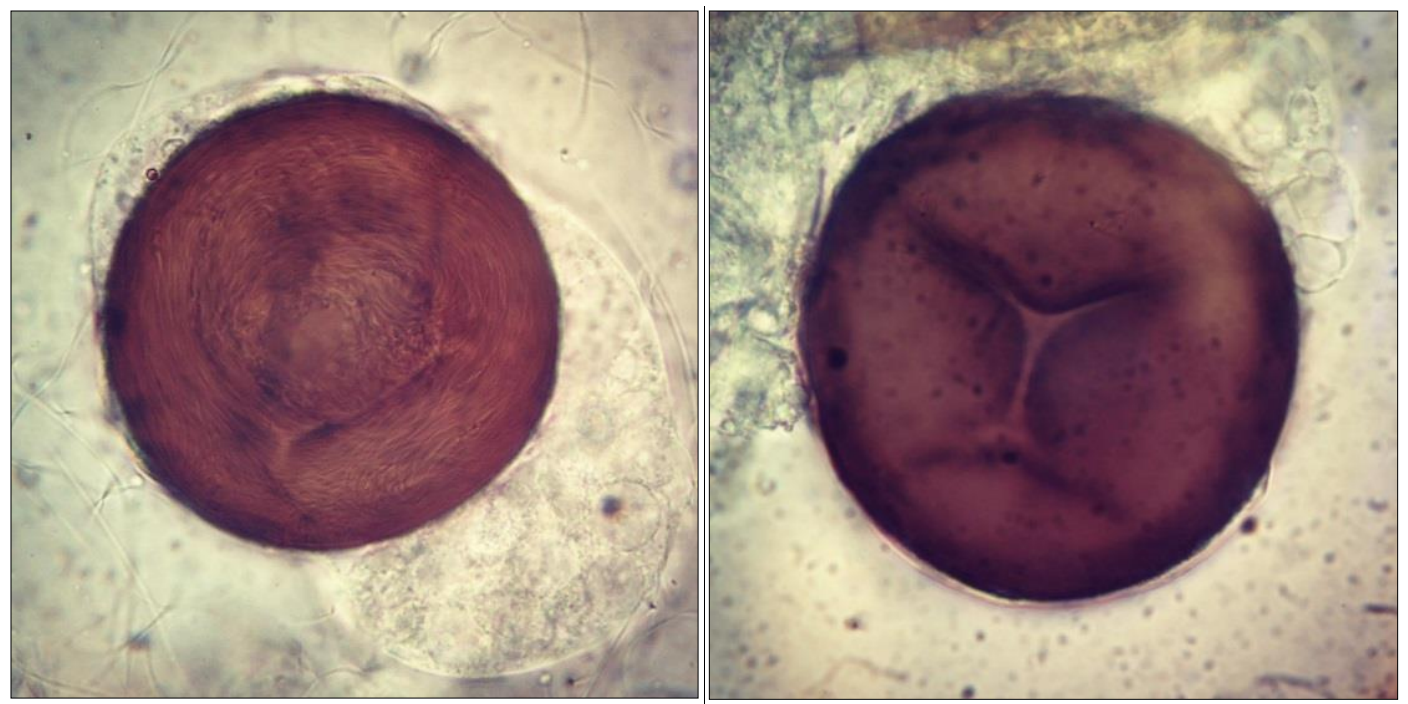

Figure 2.3. Inseminated and Un-inseminated Spermathecae. Females were dissected and described as inseminated (left) or un-inseminated. Photographs were taken under 100X oil immersion compound microscope. 